Article

\title{
Assessment of Overvoltage and Insulation Coordination in Mixed HVDC Transmission Lines Exposed to Lightning Strikes
}

\author{
Mansoor Asif $\mathbb{D}^{\text {, Ho-Yun Lee }} \mathbb{D}^{\mathbb{D}}$, Kyu-Hoon Park ${ }^{\mathbb{D}}$, Ayesha Shakeel and Bang-Wook Lee *(D) \\ Department of Electronic Engineering, Hanyang University, Hanyangdaehak-ro 55, Ansan 15588, Korea; \\ mansoor1991@hanyang.ac.kr (M.A.); hoyun05@hanyang.ac.kr (H.-Y.L.); herochin@hanyang.ac.kr (K.-H.P.); \\ ayeshash@hanyang.ac.kr (A.S.) \\ * Correspondence: bangwook@hanyang.ac.kr; Tel.: +82-031-400-4752
}

Received: 2 October 2019; Accepted: 3 November 2019; Published: 5 November 2019

check for updates

\begin{abstract}
Many geographical constraints and aesthetic concerns necessitate the partial use of cable sections in the High Voltage DC (HVDC) transmission line, resulting in a mixed transmission line. The overhead sections of mixed lines are exposed to lightning strikes. The lightning strikes can not only result in flashover of overhead line (OHL) insulators but can enter the cable and permanently damage its insulation if adequate insulation coordination measures are not taken. In this work, we have analyzed the factors that affect the level of overvoltage inside the cable by simulating a fast front model in PSCAD. It has been determined that surge arresters must be provided at cable terminals when the length of cable sections is less than $16 \mathrm{~km}$ to limit the core-ground overvoltage within the lightning impulse protective level (LIPL). The level of sheath-ground overvoltage is independent of the length of cable; however, it can be limited within LIPL by lowering the sheath grounding impedance to $1.2 \Omega$. Insulation coordination measures do not impact the likelihood of OHL insulators' flashover. The flashover performance of OHL can be improved by lowering the footing impedance of the second tower closest to the cable terminals, which is otherwise most likely to flashover.
\end{abstract}

Keywords: cable overvoltage; DC transmission; dielectric breakdown; electromagnetic transient simulation; high voltage; insulation coordination; negative lightning strikes

\section{Introduction}

HVDC transmission found its first commercial application over five decades ago. The practicality of HVDC projects at that time was limited due to high cost and technical challenges. HVDC transmission projects were deemed suitable for either long distance terrestrial power transmission where they would offer economy over the HVAC transmission, or submarine energy transmission where HVAC transmission was excessively inefficient [1,2]. With the advancement in converter technologies HVDC systems are becoming more and more cost effective and technically viable. Therefore, the application of HVDC transmission has experienced a tremendous growth over the past two decades.

The use of cable section between overhead line sections is sometimes necessitated due to geographical constraints or concern of visually polluting scenic landscapes. Such transmission lines are called mixed HVDC transmission lines. Nearly $25 \%$ of the existing HVDC transmission projects fall into this category. The lightning can strike the overhead sections of the mixed line. The resulting overvoltage surge can not only cause the flashover of OHL insulators but can also travel towards the cable. If the overvoltage inside the cable exceeds the lightning impulse withstand level (LIWL) of insulation layers of the cable a permanent failure of cable is possible [3-5]. Therefore, the possibility of such events should be thoroughly analyzed, and overvoltage protection strategies should be considered. 
Many researchers have studied the impact of lightning strikes on mixed transmission lines since the 1990s and several resulting articles have attempted to address various aspects of lightning transients in mixed HVDC as well as HVAC lines [6-16]. Many of these studies focused on specific design aspects such as the shunt reactor on cable terminal, presence of surge arrester/sheath voltage limiter, OHL geometries and tower footing impedance. Others focused on the modelling details such as corona, frequency dependent sheath grounding impedance as well as tower footing impedance. In our previous study [15], we presented a thorough theoretical analysis supported by fast front transient simulation regarding the transient behavior of mixed HVDC transmission lines. The insulators of OHL most vulnerable to flashover were identified and the reason for their high vulnerability was explained.

In this paper we have analyzed the maximum overvoltage stresses experienced by the cables' insulation layer by simulating a high frequency model of mixed HVDC transmission line in time domain simulation software PSCAD (X4, v4.6.2). We have found that the core-ground overvoltage in a cable is dependent on the length of the cable. Due to the positive reflection coefficient at the receiving end boundary of the cable, the voltage surges reflected from the boundary have the same polarity as the incident surge and they superimpose resulting in amplification of voltage inside the cable. Sheath-ground overvoltage on the other hand are independent of cable length due to the negative reflection coefficient at their receiving end boundary. The surge arrester must be provided at the terminals of the small cables to provide an adequate protection margin to the cable's main insulation layer, whereas in longer cables the use of a surge arrester is not necessary. The sheath-ground overvoltage can be limited within the lighting impulse protection level (LIPL) of the jacket by lowering the sheath grounding impedance.

It has been found that the insulation coordination measures do not alter the transient behavior of the mixed transmission line studied in our previous work [15]. The second tower closest to the cable boundary remains most vulnerable to flashover despite the installation of a surge arrester at cable terminals and lowering the sheath grounding impedance. However, the possibility of flashover of the positive pole insulator can be eliminated by lowering the footing impedance of the aforementioned tower.

In the following sections we have explained the system and details of fast front transient models, results and discussion and finally the conclusion.

\section{System Description and Fast Front Transient Models}

In this work we have considered a $\pm 500 \mathrm{kV}$ bipolar mixed HVDC transmission system shown in Figure 1. A cable with finite length up to $100 \mathrm{~km}$ is used for analysis. The sheath of the cable is grounded at the terminals. Five towers closest to both of the cable terminals are represented in detail. The overhead line is terminated with matching impedance at both ends to emulate an infinite transmission line.

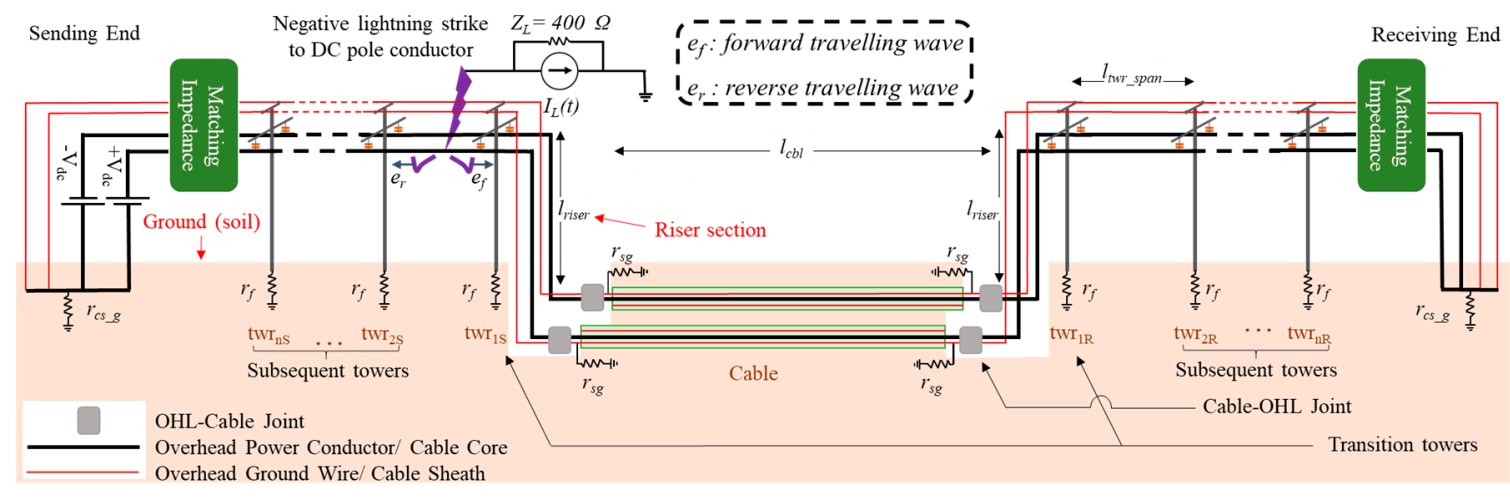

Figure 1. Fast front model of mixed High Voltage DC (HVDC) transmission line for analysis of lightning transients. A finite cable section is present between two overhead line sections terminating in matching impedance to avoid reflection of voltage surge from remote ends of the transmission line (description of symbols is provided in Table 1). 
Fast front models of various components used to represent the mixed HVDC transmission system are described below.

Table 1. Values of electromagnetic transient (EMT) simulation model parameters.

\begin{tabular}{ccc}
\hline Symbol & Quantity & Value \\
\hline $\mathrm{h}$ & Height of tower & $47 \mathrm{~m}$ \\
$l_{t 1}$ & Length of upper tower segment & $4 \mathrm{~m}$ \\
$l_{t 2}$ & Length of lower tower segment & $43 \mathrm{~m}$ \\
$Z_{T}$ & Characteristic impedance of tower segments & $139 \Omega$ \\
$r_{f}$ & Footing impedance & $10 \Omega$ \\
$r_{\text {sg }}$ & Sheath-grounding impedance & $10 \Omega$ \\
$c_{\text {ins }}$ & Capacitance of insulator & $2.75 \mathrm{pF}$ \\
$L_{\text {arc }}$ & Insulator arc inductance & $5 \mu \mathrm{H}$ \\
$l_{\text {tworspan }}$ & Length of tower span & $350 \mathrm{~m}$ \\
$v_{\text {sheath }}$ & Wave velocity on cable sheath & $2.7 \times 10^{7} \mathrm{~m} / \mathrm{s}$ \\
$v_{\text {core }}$ & Wave velocity on cable core & $6.4 \times 10^{7} \mathrm{~m} / \mathrm{s}$ \\
$v_{O H P C}$ & Wave velocity on OHPC & $2.8 \times 10^{8} \mathrm{~m} / \mathrm{s}$ \\
$v_{\text {OHGW }}$ & Wave velocity on OHGW & $2.8 \times 10^{8} \mathrm{~m} / \mathrm{s}$ \\
$Z_{\text {sheath }}$ & Characteristic impedance of cable sheath & $27.1 \Omega$ \\
$Z_{\text {core }}$ & Characteristic impedance of cable core & $72.7 \Omega$ \\
$Z_{\text {OHGW }}$ & Characteristic impedance of OHGW & $541.8 \Omega$ \\
$Z_{O H P C}$ & Characteristic impedance of OHPC & $465.3 \Omega$ \\
$v_{t w r}$ & Wave velocity on tower segments & $2.55 \times 10^{8} \mathrm{~m} / \mathrm{s}$ \\
$l_{\text {riser }}$ & Length of riser section & $50 \mathrm{~m}$ \\
$K$ & Leader coefficient & $1.3 \mathrm{~m} / 2 / \mathrm{kV} \mathrm{V}^{2} \mathrm{~s}$ \\
$E_{0}$ & Time of lightning strike & $600 \mathrm{kV} / \mathrm{m}$ \\
$y$ & Critical leader inception gradient & $0.007 \mathrm{~s}$ \\
\hline
\end{tabular}

\subsection{Tower}

To emulate the overvoltage stress experienced by the insulators accurately, the vertical section of the tower is split into two sections connected at cross arms as shown in Figure 2b.

Due to the relatively small structure of HVDC towers, the multistorey tower models [17-19] yield inaccurate results. Therefore, we have represented the HVDC tower by a frequency independent distributed parameter line model composed of single conductor. The characteristic impedances of upper and lower tower sections are considered to be same [20,21].

Cross arms and braces retard the wave propagation on the tower. Therefore, the wave velocity of the vertical tower section is $85 \%$ of the speed of light [22]. The characteristic impedance of the waisted tower structure, shown in Figure 2, is calculated using Equation (1) [23].

$$
Z_{T}=60 \ln \left\{\cot \left(\frac{1}{2} \tan ^{-1} T\right)\right\}
$$

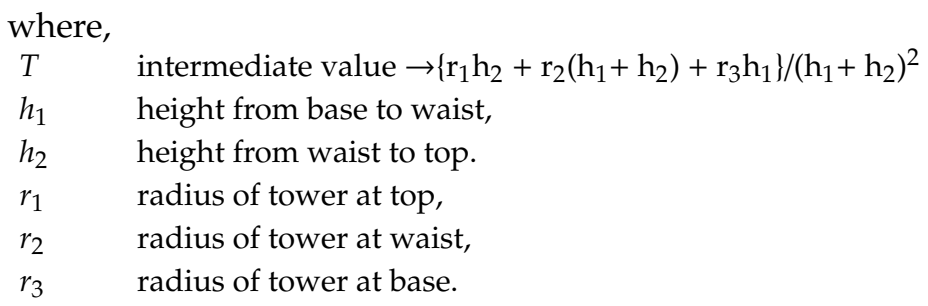




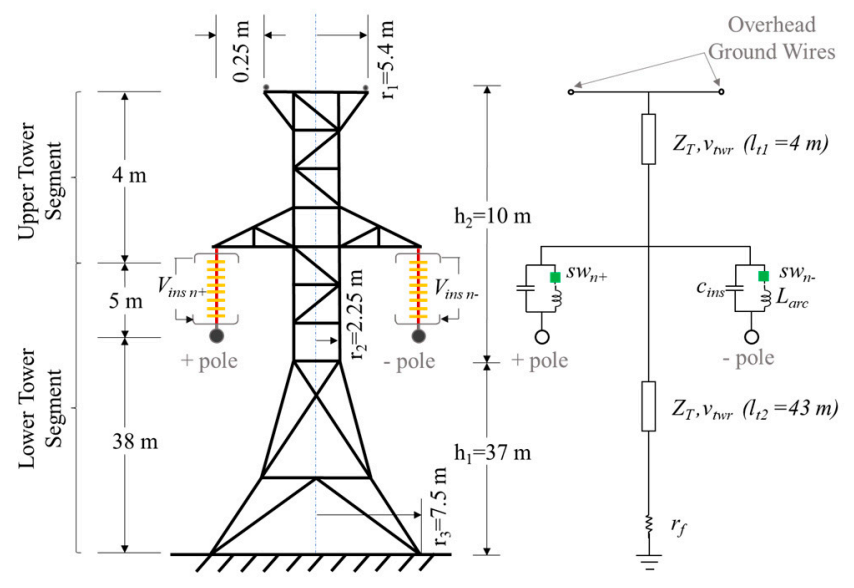

(a)

(b)

Figure 2. Overhead section of mixed HVDC transmission line. (a) Structure. (b) Fast front model for electromagnetic transient (EMT) simulation (description of symbols is provided in Table 1 and Equation (1)) [15].

\subsection{Footing Impedance of Tower}

The level of overvoltage on the top of the tower and overvoltage stress experienced by OHL insulators is strongly dependent on the tower footing impedance. Therefore, prudently selecting a model of footing impedance is vital to obtaining reliable results.

The impedance of high resistivity soil has strong frequency dependence [24,25]. However, frequency dependent models have shown optimistic results regarding lightning overvoltage [14]. Moreover, the extent of frequency dependence of soil depends on resistivity which varies considerably according to the time of year. Therefore, to conservatively estimate overvoltage, we have represented the footing impedance by a fixed resistance $r_{f}[15,17,18]$.

\subsection{Insulators}

Suspension insulators shown in Figure 2 are comprised of twenty-nine disks of serially connected cap and pin type ceramic insulators ( $80 \mathrm{pF} /$ disk). The air gap between arc horns is $5 \mathrm{~m}$ [26].

The flashover of an insulator is predicted using a leader propagation model (LPM). The time taken to breakdown is calculated by taking into account the physics of the discharge process and the gap configuration [27]. The total breakdown time, $t_{c}$ is given by Equation (2):

$$
t_{c}=t_{i}+t_{s}+t_{l}
$$

where,

$t_{i} \quad$ Corona inception time, $\mu \mathrm{s}$

$t_{l} \quad$ Leader propagation time, $\mu \mathrm{s}$

$t_{s} \quad$ Streamer propagation time, $\mu \mathrm{s}$

The corona inception voltage is very small compared to the breakdown voltage. The corona inception time $t_{i}$ is negligible, owing to the swift increase in voltage, and is assumed to be zero. If the voltage keeps increasing after the corona inception, a streamer begins to grow and cross the gap after time $t_{s}$, in Equation (3):

$$
\frac{1}{t_{s}}=1.25\left(\frac{E}{E_{50}}\right)-0.95
$$

where,

$E_{50} \quad$ Average gradient at the critical flashover (CFO) voltage, $\mathrm{kV} / \mathrm{m}$

E Maximum gradient in the gap before breakdown, $\mathrm{kV} / \mathrm{m}$ 
After $t_{s}$ a leader starts to develop, with an exponentially increasing velocity given by (4),

$$
\frac{d L}{d t}=K V(t)\left[\frac{V(t)}{g-L}-E_{0}\right]
$$

where,

$L \quad$ Leader length, $\mathrm{m}$

g Gap length, $\mathrm{m}$

$V(t) \quad$ Voltage across gap, $\mathrm{kV}$

$\mathrm{K} \quad$ Leader coefficient, $\mathrm{m}^{2} / \mathrm{kV}^{2}$.s

$E_{0} \quad$ Critical leader inception gradient, $\mathrm{kV} / \mathrm{m}$

$K$ and $E_{0}$ for cap and pin type suspension insulators under negative polarity stress are given in Table 1. Leader crosses the gap after time $t_{l}$ and the breakdown occurs.

The breakdown of the insulator is emulated by a switch. Equivalent capacitance $c_{i n s}$, of the insulator as shown in Figure $2 b$ is connected in parallel to the switch. The inductive characteristics of the arc path are represented by an inductance $L_{\text {arc }}$ connected in series with the switch [28].

\subsection{Transmission Line}

The cables and overhead lines are represented using the frequency dependent (phase) model commonly known as the universal line model (ULM). The ULM can adequately represent the transmission line for a wide range of frequencies $[29,30]$.

The cable and overhead conductor are chosen to have a power rating of $660 \mathrm{MW} /$ pole of the HVDC line. Midspan conductor sag for Overhead Power Conductors (OHPCs) as well as Overhead Ground Wires (OHGWs) is chosen as $10 \mathrm{~m}$. OHGWs are modelled using $\frac{1}{2}$ high strength steel, whereas Parrot ACSR 54/19 is used to model the OHPCs.

The $500 \mathrm{kV}$ underground cables with a conductor cross section of $2100 \mathrm{~mm}^{2}$ are based on [31]. The two cables of the bipolar system are placed horizontally as shown in Figure 3. The main insulation layer of the cable has a lightning impulse withstand level (LIWL) of 2.7 p.u., whereas the jacket has a LIWL of 0.2 p.u. To ensure reliability and longevity, a protection margin of $20 \%$ should be provided [5].

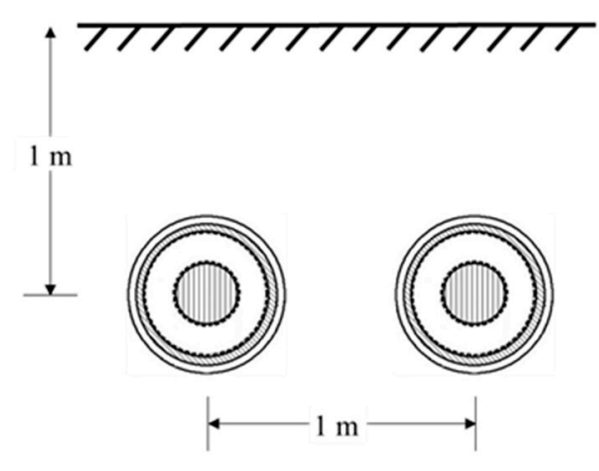

(a)

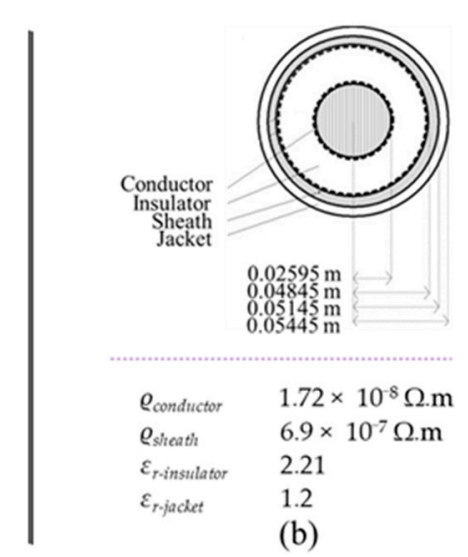

(b)

Figure 3. Underground section of mixed HVDC transmission line (a) layout, (b) dimensions and electrical properties.

Wave velocity and characteristic impedance of cable and overhead line conductors are calculated using the line constant program (LCP) of PSCAD and are listed in Table 1.

\subsection{Lightning Strike}

The Lightning strike is represented by a current source connected in parallel with the resistance. The parallel resistance emulates the impedance of the lightning channel [32]. 
A lightning current waveform with an upwardly concave front, as shown in Figure 4, resembles closely the records of lightning current wave-shapes given in $[27,33]$. The mathematical representation of this waveshape can be seen in Equation (5):

$$
i(t)=\left\{\begin{array}{c}
A t+B t^{n}, \quad t<t_{n} \\
I_{1} \mathrm{e}^{-\frac{\left(\mathrm{t}-t_{n}\right)}{t_{1}}}-I_{2} \mathrm{e}^{-\frac{\left(\mathrm{t}-t_{n}\right)}{t_{2}}}, \quad t>t_{n}
\end{array}\right.
$$

constants of the wave shape listed in Table 2, have been derived according to [27].

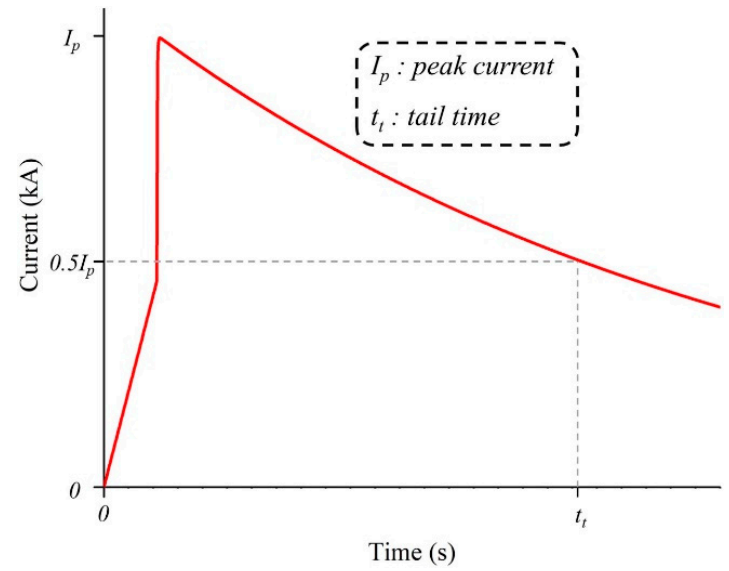

(a) Normal

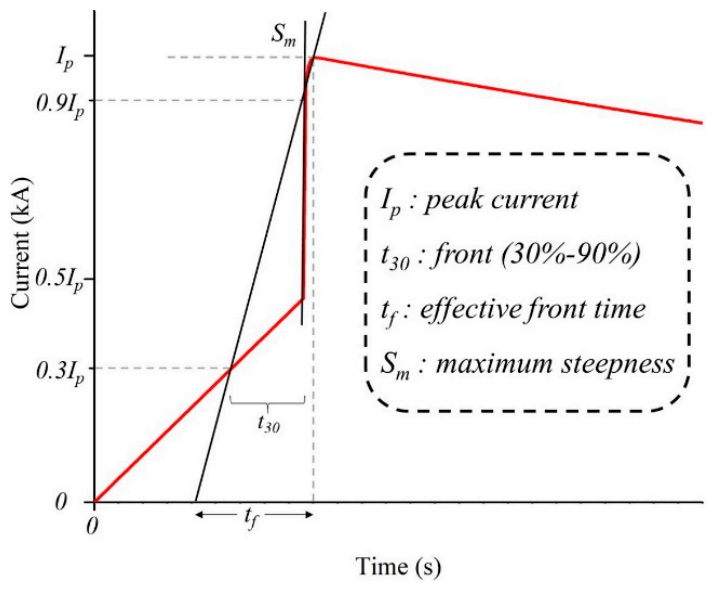

(b) Zoomed

Figure 4. Upwardly concave front lightning current wave shape [27].

Table 2. Lightning impulse current parameters.

\begin{tabular}{cccc}
\hline & Parameters of Strike & OHPC Strike & OHGW/Tower Top Strike \\
\hline$I_{p}$ & peak current & $20 \mathrm{kA}$ & $200 \mathrm{kA}$ \\
$t_{30}$ & front $(30 \%-90 \%)$ & $3 \mu \mathrm{s}$ & $8 \mu \mathrm{s}$ \\
$t_{f}$ & effective front time & $5 \mu \mathrm{s}$ & $13.33 \mu \mathrm{s}$ \\
$t_{t}$ & tail time & $77.5 \mu \mathrm{s}$ & $200 \mu \mathrm{s}$ \\
$S_{m}$ & maximum steepness & $20 \mathrm{kA} / \mu \mathrm{s}$ & $48 \mathrm{kA} / \mu \mathrm{s}$ \\
$n$ & wave-shape constant & 18.6 & 11.171 \\
$A$ & $/ /$ & $1.061 \mathrm{kA} / \mu \mathrm{s}$ & $4.325 \mathrm{kA} / \mu \mathrm{s}$ \\
$B$ & $/ /$ & $3.257 \times 10^{-17} \mathrm{kA} / \mu \mathrm{s}$ & $9.247 \times 10^{-14} \mathrm{kA} / \mu \mathrm{s}$ \\
$t_{n}$ & $/ /$ & $8.653 \mu \mathrm{s}$ & $21.858 \mu \mathrm{s}$ \\
$t_{1}$ & $/ /$ & $99.324 \mu \mathrm{s}$ & $257.004 \mu \mathrm{s}$ \\
$t_{2}$ & $/ /$ & $0.1 \mu \mathrm{s}$ & $0.416 \mu \mathrm{s}$ \\
$I_{1}$ & $/ /$ & $20.020 \mathrm{kA}$ & $200.324 \mathrm{kA}$ \\
$I_{2}$ & $/ /$ & $2.0201 \mathrm{kA}$ & $20.324 \mathrm{kA}$ \\
\hline
\end{tabular}

The total probability of a lightning current exceeding $200 \mathrm{kA}$ is $0.77 \%$ [33]. Therefore, the peak magnitude of the lightning strike applied to OHGWs or the tower top is chosen to be $200 \mathrm{kA}$. The IEEE modelling guideline also recommends the same for insulation coordination studies [26].

$$
I_{M S F}=\left[\frac{\gamma\left(h_{m}+h_{p}\right) / 2}{A(1-\gamma \sin \alpha)}\right]^{1 / B}
$$

The, maximum shielding failure current $\left(I_{M S F}\right)$ is calculated by using an electro-geometric model (EGM) proposed by IEEE Std [34]. By solving Equation (6) based on the geometric model given in Figure 5 , the $I_{M S F}$ is calculated to be $20 \mathrm{kA}$. Where, $h_{m}$ : Height of OHGWs, $h_{p}$ : Height of OHPCs, $\alpha, \beta$ 
and $\gamma$ are as recommended by IEEE Standard are as follows. $\alpha$ : Shielding angle, $\beta=0.36+0.17 \ln (43-$ $\left.h_{p}\right) \Rightarrow h_{p} \leq 40 \mathrm{~m}, \gamma: 1 / \beta$ : the parameters of the lightning impulse wave shape are listed in Table 2.

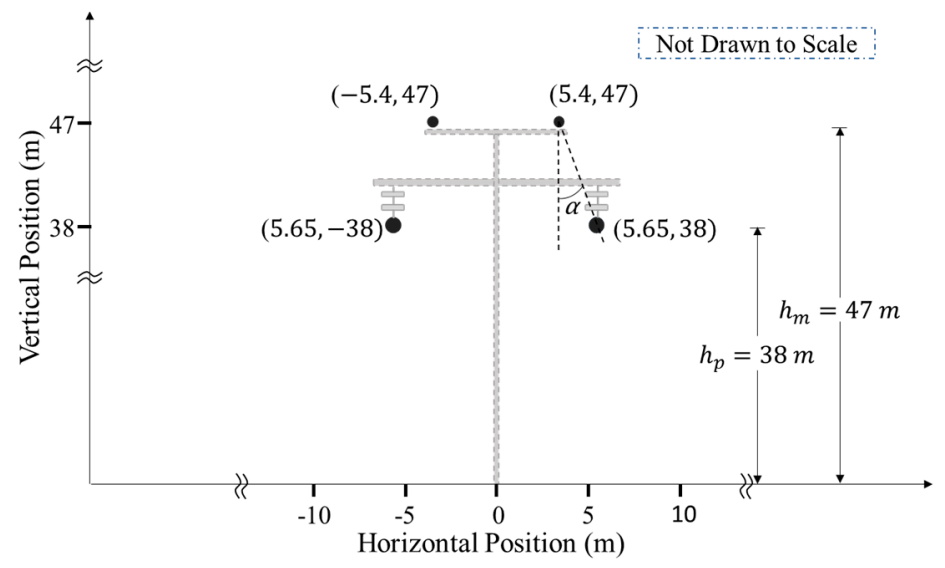

Figure 5. Geometric model of tower for application of an electro-geometric model (EGM) to calculate the shielding failure current $\left(I_{M S F}\right)$.

\subsection{Surge Arrester}

The internal overvoltages in the line commutated converter (LCC) HVDC system are not expected to exceed 1.5 p.u. for the maximum duration of $100 \mathrm{~ms}$. The insulation of the HVDC cable is capable of withstanding this stress and therefore protection does not need to be provided against internal overvoltages [5].

The lightning strikes on the overhead sections of the line would expose the cable to overvoltage stress, which can lead to permanent damage of the cable if the said overvoltage exceeds the LIWL of the insulation layer of cable. The level of overvoltage in the cable resulting from lightning strikes depends on several design parameters of the mixed HVDC transmission line.

Since there is no need to provide protection against internal overvoltage, a surge arrester with a maximum continuous operating voltage (MCOV) of $750 \mathrm{kV}$, i.e., 1.5 p.u. of the system voltage, and the following protective characteristics will be employed if the voltage inside the unprotected cable exceeds 2.25 p.u. [6].

- $\quad$ Lightning impulse protective levels (LIPL), $\mathrm{V}_{10}: 1130 \mathrm{kV}(10 \mathrm{kA}, 8 \times 20 \mu \mathrm{s})$

- Switching impulse protective levels (SIPL), $\mathrm{V}_{\mathrm{ss}}: 960 \mathrm{kV}(3 \mathrm{kA}, 30 \times 60 \mu \mathrm{s})$

The lightning impulse protection margin for this surge arrester can be calculated using Equation (7).

$$
P M=\left(\frac{L I W L}{L I P L}-1\right) * 100
$$

This provides a desired protection margin (PM) of $20 \%$ which is in accordance with the recommended minimum level of 20\% for HVDC cables [5].

Metal oxide surge arresters (MOSA) are used universally for providing protection against surge voltages in a range of power system applications. However, the residual voltage across the arrester is a function of both the rate of rise and the magnitude of the current conducted by the arrester. The waveshape of the voltage impressed on the surge arrester can vary considerably depending on the location of incidence of the lightning strike and on the characteristics of the lightning strike and of mixed transmission line.

In order to emulate the characteristics of a real MOSA, a frequency dependent model proposed by IEEE WG 3.4.11 shown in Figure 6 will be used in this paper [35].

The nonlinear V-I characteristic of an arrester is represented using two nonlinear resistors $\mathrm{A}_{0}$ and $A_{1}$, shown in the Figure 7 . The nonlinear resistors are separated by an RL filter, which offers very low 
impedance to slow front surges, resulting in parallel conduction of the two resistors. However, for fast front surges the impedance of the RL section become quite significant. Therefore, more current is conducted by the nonlinear resistance ' $\mathrm{A}_{0}$ '. This results in a higher voltage across arrester terminals because the nonlinear resistor ' $\mathrm{A}_{0}$ ' has a higher voltage for a given current than the resistor ' $\mathrm{A}_{1}$ ', as can be seen in Figure 7. These V-I characteristics are obtained by modifying the characteristics proposed in [35] to match the $V_{10}$ and $V_{S S}$ required in this study.

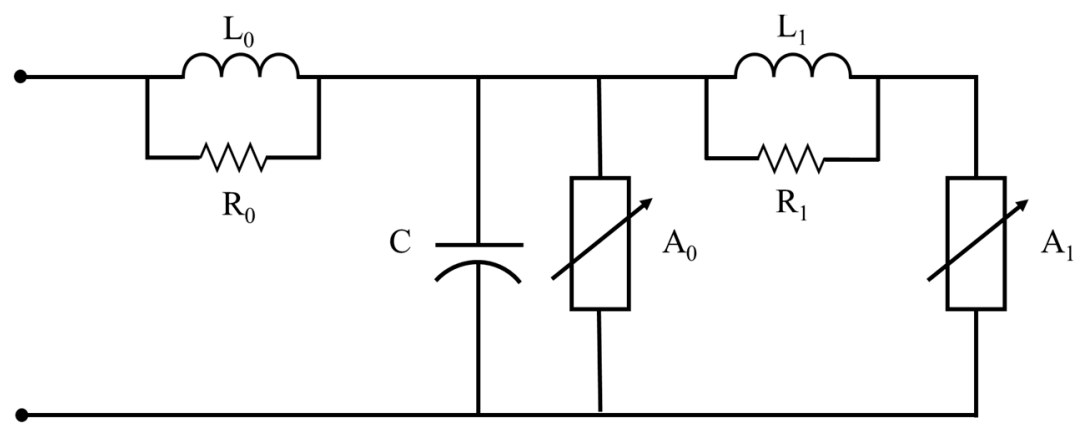

Figure 6. Frequency dependent surge arrester model.

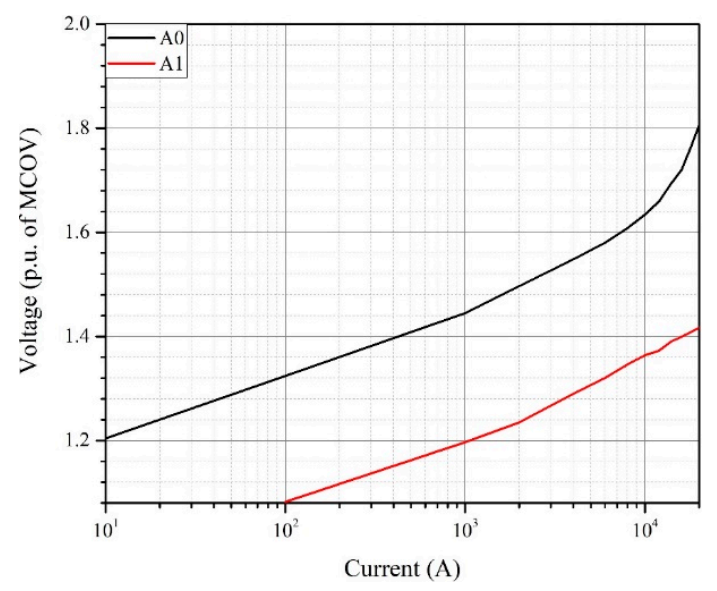

Figure 7. Residual voltage across non-linear resistors as a function of the impulse current.

The inductance ' $\mathrm{L}_{0}$ ' in the model represents the magnetic field in the vicinity of the surge arrester, whereas the capacitor ' $C$ ' represents the terminal-to-terminal capacitance of the arrester.

The parameters of the surge arrester model can be calculated using Equations (8)-(12).

$$
\begin{aligned}
& L_{1}=15 \frac{d}{n} \mu \mathrm{H} \\
& R_{1}=65 \frac{d}{n} \Omega \\
& L_{0}=0.2 \frac{d}{n} \mu \mathrm{H} \\
& R_{0}=100 \frac{d}{n} \Omega \\
& C=100 \frac{n}{d} \mathrm{pF}
\end{aligned}
$$

where,

$d \quad$ height of the arrester $[\mathrm{m}]$

$n$ number of parallel columns of metal oxide in arrester 
The parameters of the surge arrester model are listed in Table 3.

Table 3. Parameters of the surge arrester model

\begin{tabular}{cc}
\hline Components of Surge Arrester Model & $\boldsymbol{n = 1 ,} \mathbf{d = 6} \mathbf{m}$ \\
\hline$L_{1}$ & $90 \mu \mathrm{H}$ \\
$R_{1}$ & $390 \Omega$ \\
$L_{0}$ & $1.2 \mu \mathrm{H}$ \\
$R_{0}$ & $600 \Omega$ \\
$C$ & $16.66667 \mathrm{pF}$ \\
\hline
\end{tabular}

\section{Results and Discussion}

Lightning can strike the overhead power conductors (OHPC) or the overhead ground wire (OHGW) and tower top as discussed previously. In this section we will present and analyze in detail the overvoltage stresses experienced by the insulation layers of the cable resulting from lightning strikes. We will further analyze whether these overvoltages exceed the lightning impulse withstand level (LIWL) of the cable and whether insulation coordination measures are necessary. Various insulation coordination measures will be analyzed. Finally, the impact of insulation coordination on transient behavior of a mixed HVDC transmission line will be presented and analyzed in depth.

\subsection{Overvoltage Analysis}

The lightning strikes closest to the cable, i.e., on the transition tower will cause the maximum overvoltage in the cable. The strike on the OHPC of the transition tower will enter the cable and cause core-ground (CG) as well as sheath-ground (SG) overvoltage, whereas a strike on the tower top or OHGW will result in sheath-ground (SG) overvoltage.

\subsubsection{Lightning Strike on an Overhead Power Conductor}

\section{Core-Ground Overvoltage}

Negative lightning strikes are most likely to occur [27]. A negative lightning strike on a negative pole OHPC at $\mathrm{twr}_{1 \mathrm{~S}}$ will result in the constructive superposition of voltage, hence subjecting the cable to the highest overvoltages. The equivalent circuit is shown in Figure 8. Only two towers are represented in detail in this equivalent circuit. The OHPC can be seen to be isolated from the tower by an open switch. Therefore, a negative lightning strike on a negative OHPC can initiate a voltage surge $\mathrm{e}_{\mathrm{f} 1}$ travelling on the OHPC in the forward direction towards the cable and another voltage surge $\mathrm{e}_{\mathrm{r} 0}$ traveling towards the DC source in the reverse direction as shown on the equivalent circuit in Figure 8. A portion of the wave $\mathrm{e}_{\mathrm{f} 2}$ is refracted inside the cable, whereas the rest, $\mathrm{e}_{\mathrm{r} 1}$, is reflected backward at boundary a. The wave $e_{\mathrm{f} 2}$ travelling forward inside the cable will be again reflected and refracted at the receiving end boundary ' $b$ ' of the cable. The magnitude of reflected and refracted waves can be determined by a traveling wave theory as per Equations (13)-(15).

$$
\begin{aligned}
& e_{f 2}=e_{f 1} \frac{2 * Z_{\text {core }}}{Z_{\text {OHPC }}+Z_{\text {core }}} \\
& e_{r 1}=e_{f 1} \frac{Z_{\text {core }}-Z_{\text {OHPC }}}{Z_{\text {OHPC }}+Z_{\text {core }}} \\
& e_{r 2}=e_{f 2} \frac{Z_{\text {OHPC }}-Z_{\text {core }}}{Z_{\text {OHPC }}+Z_{\text {core }}}
\end{aligned}
$$

The simulation results for the resulting overvoltage at the boundary ' $a$ ', i.e., the entrance of a cable according to cable length are shown in Figure 9. 


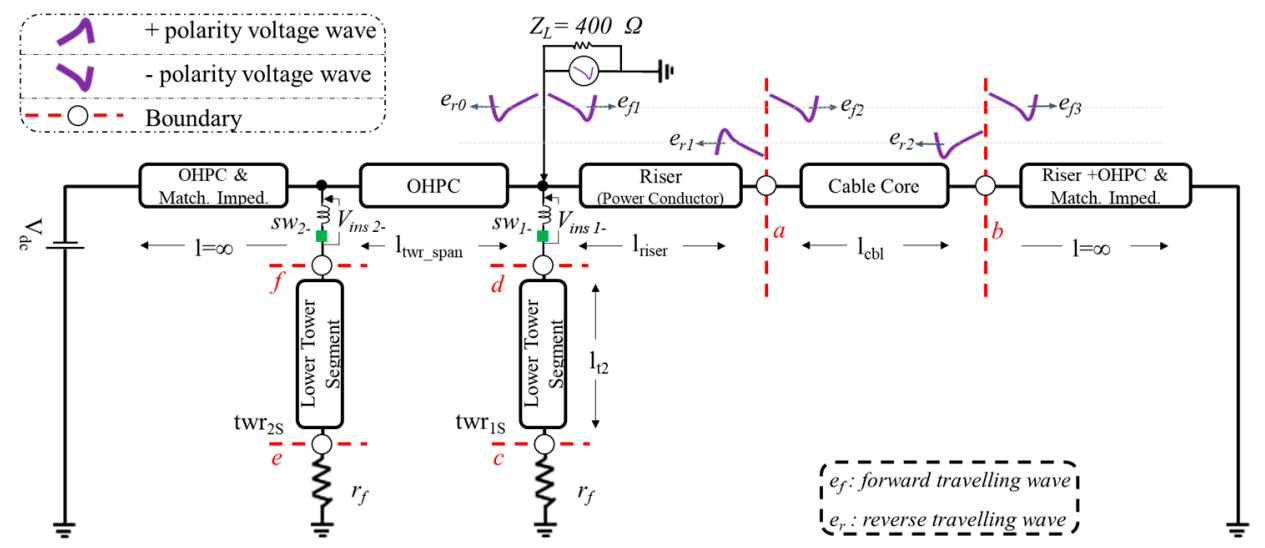

Figure 8. An equivalent circuit of a mixed HVDC transmission line for analysis of direct lightning strikes on overhead power conductors (OHPCs) at a negative pole (only the two towers closest to the sending end of the cable are shown) (description of symbols is provided in Table 1). [15].

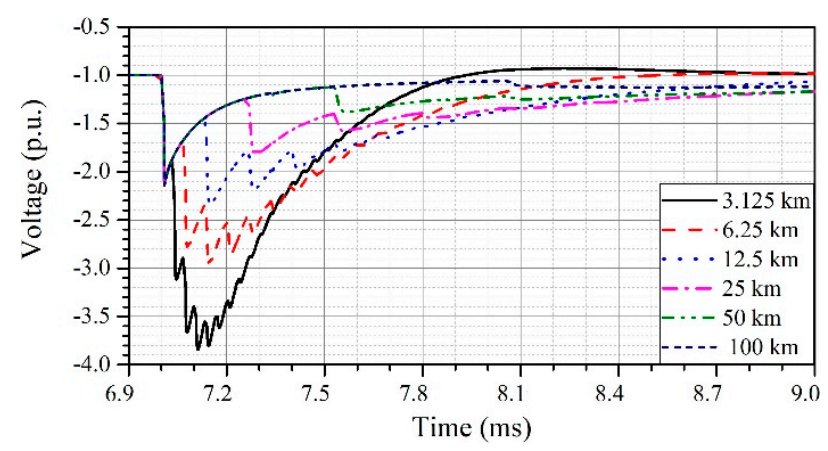

Figure 9. Core-ground overvoltage at the entrance of a cable according to the length of the cable.

It can be seen that, as the length of cable decreases, the magnitude of overvoltage increases. The characteristic impedance of the OHPC is much higher than that of the cable core conductor, making the reflection coefficient positive. Therefore, as the voltage surge travels from the cable to the OHPC, the same polarity surge is reflected from their boundary ' $b$ '. In a shorter cable section, the reflected wave arrives at the sending end very quickly and without sufficient attenuation. This same polarity reflected voltage surge superimposes with the incident surge resulting in an increase in the magnitude of the overvoltage. It can be seen that in the cable sections shorter than $12.5 \mathrm{~km}$, multiple reflections superimpose on the incident surge even before the tail of the incident surge reaches its $50 \%$ value.

On the other hand, in a $100 \mathrm{~km}$ long cable section, the reflected wave arrives just before $8.1 \mathrm{~ms}$. The incident wave reduces to less than $10 \%$ before the arrival of the reflected wave. Moreover, due to the longer distance, the reflected wave is highly attenuated. Therefore, it can be seen that in longer cable sections the maximum overvoltage depends only on the magnitude of the lightning strike and characteristics impedances of the OHL and the cable.

However, the maximum overvoltage does not always occur at the entrance of the cable. Therefore, to determine the maximum overvoltage, the cables with the lengths shown in Figure 9 are divided into ten segments. The voltage at the boundaries of each section is calculated. The results are presented in Figure 10.

To easily visualize the results of Figure 10, the plot of the maximum overvoltage along the length of the cable is shown in Figure 11. The location and magnitude of the maximum overvoltage in each case is listed in Table 4. 


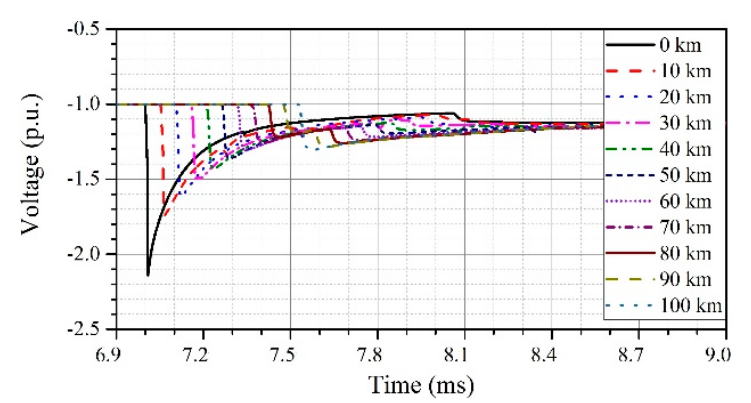

(a) $100 \mathrm{~km}$ cable

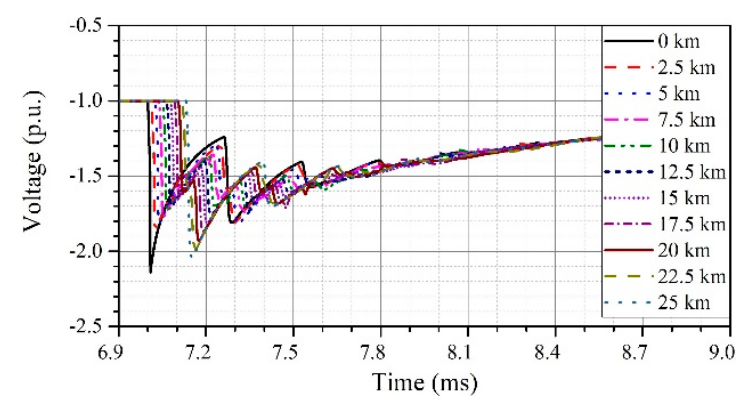

(c) $25 \mathrm{~km}$ cable

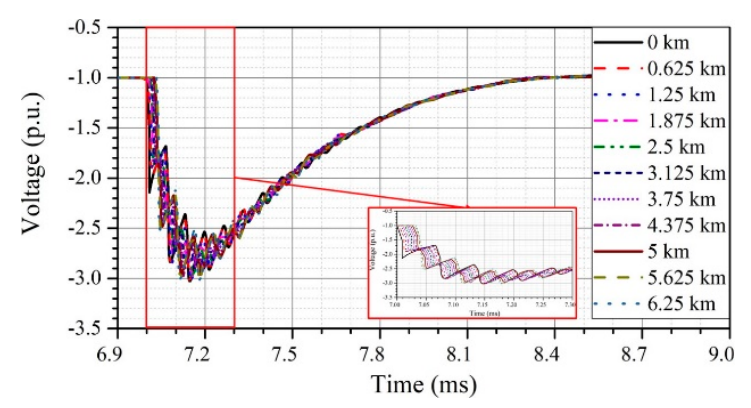

(e) $6.25 \mathrm{~km}$ cable

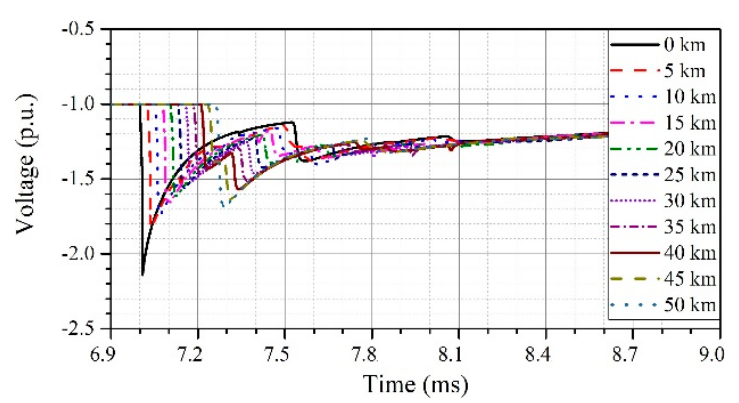

(b) $50 \mathrm{~km}$ cable

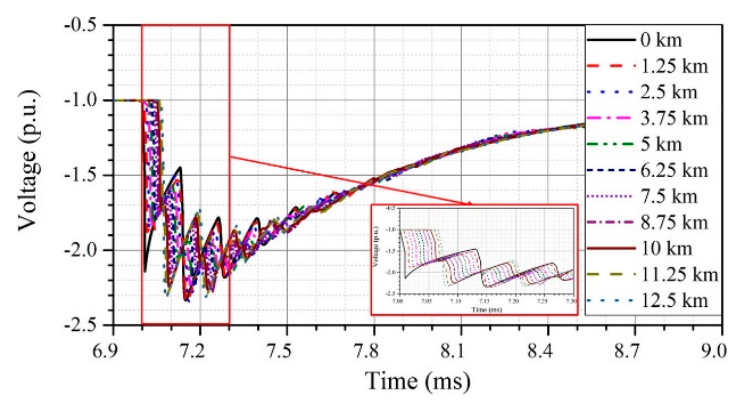

(d) $12.5 \mathrm{~km}$ cable

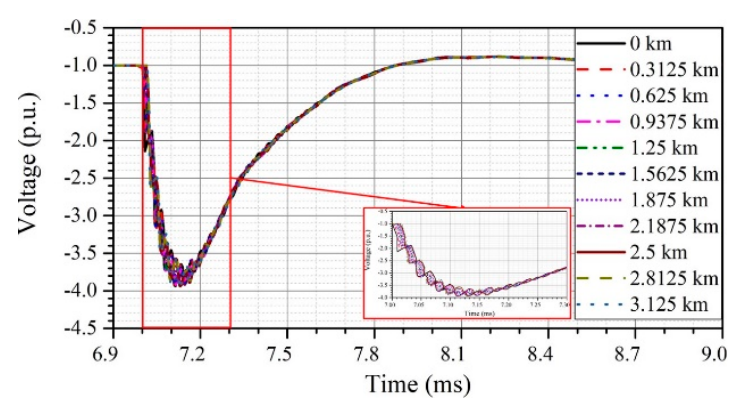

(f) $3.125 \mathrm{~km}$ cable

Figure 10. Core-ground overvoltage at ten equally spaced intervals along the length of the cable $(3.125-100 \mathrm{~km})$.

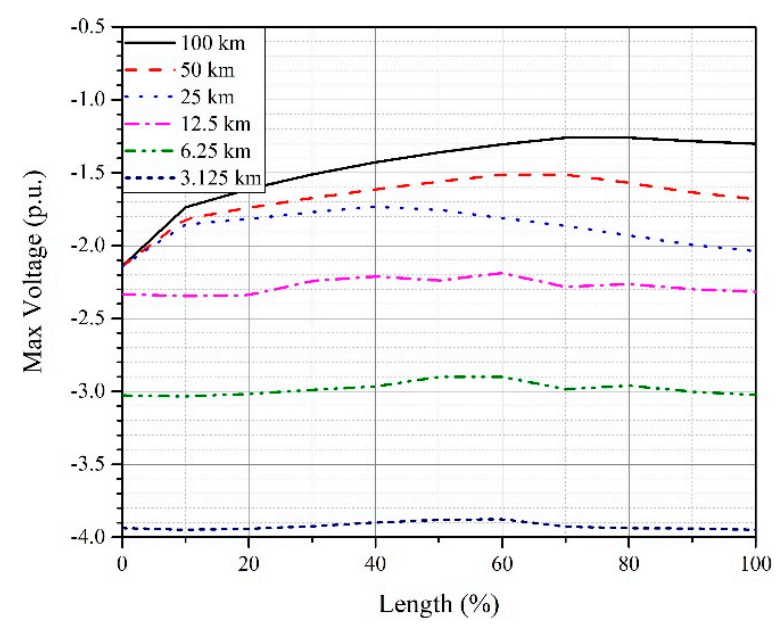

Figure 11. Maximum core-ground voltage along the length in cables with different lengths. 
Table 4. Maximum core-ground overvoltage in cables with different lengths.

\begin{tabular}{ccc}
\hline Cable Length $\mathbf{( k m )}$ & Maximum Overvoltage (p.u.) & Distance from Sending End (\%) \\
\hline 100 & -2.141 & 0 \\
50 & -2.141 & 0 \\
25 & -2.141 & 0 \\
12.5 & -2.345 & 10 \\
6.25 & -3.032 & 10 \\
3.125 & -3.948 & 10 \\
\hline
\end{tabular}

It can be seen that in longer cable sections, i.e., $100 \mathrm{~km}, 50 \mathrm{~km}$ and $25 \mathrm{~km}$, the maximum overvoltage occurs at the cable entrance. The magnitude of the maximum overvoltage decreases towards the center of the cable before increasing again near the receiving end of the cable. A close comparison of $100 \mathrm{~km}$ and $90 \mathrm{~km}$ plots in Figure 10a shows that in the case of the former, the reflected wave instantly superimposes on the incident wave upon its arrival, whereas in the case of the latter there is a displacement between the incident and the reflected wave equal to $20 \%$ of the travel time of the cable. This leads to the decrease in amplitude of the incident wave before the arrival of the reflected wave. Therefore, the magnitude of the maximum voltage continues to decrease as we move away from the receiving end.

In the shorter cable sections, i.e., $12.5 \mathrm{~km}, 6.25 \mathrm{~km}$ and $3.125 \mathrm{~km}$, the maximum overvoltage occurs at $10 \%$ from the receiving end. This can be attributed to the shorter travel times of the reflected wave, lower attenuation of the reflected wave and insufficient damping of the incident wave.

\section{Sheath-Ground Overvoltage}

The impulse current flowing through the core of the cable induces a voltage in the sheath of the cable. The voltage in the sheath of the cable stresses the jacket of the cable. If the voltage exceeds the LIWL of the jacket (0.2 p.u.), it may rupture. Therefore, in this subsection we have presented a detailed analysis of sheath-ground (SG) overvoltage considering the various factors that influence it.

The voltage at the sending end terminal of the sheath resulting from a direct lightning strike on the sending end OHPC is shown in Figure 12. It can be seen that the maximum overvoltage is the same regardless of the length of the cable. This behavior is in contradiction with the length dependent behavior of the CG overvoltage.

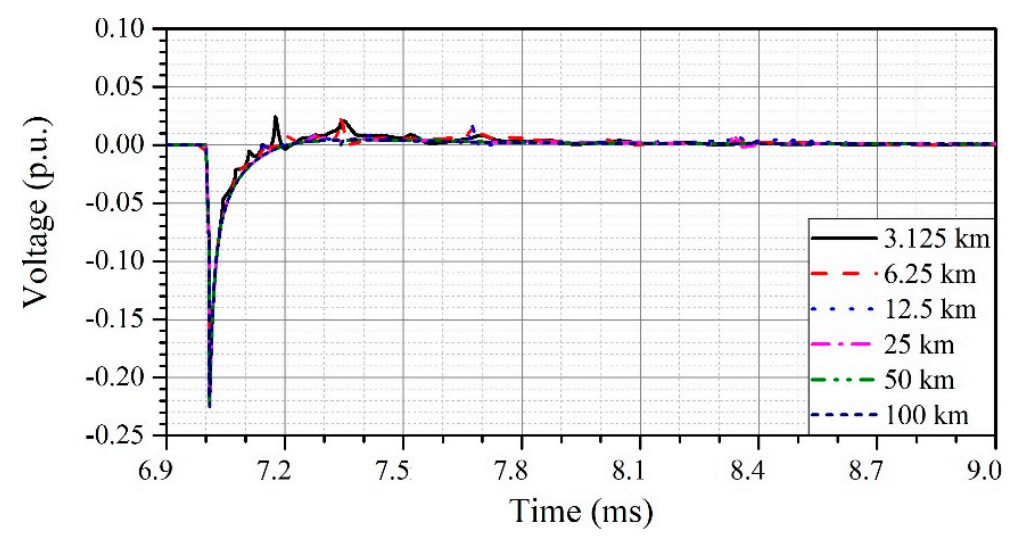

Figure 12. Sheath-ground overvoltage at the sending end terminal of the cables considering different cable lengths.

The SG overvoltage along the length of the cable at equally spaced intervals is shown in Figure 13. Compared to the CG overvoltage results shown in Figure 10, the incident wave takes much longer to arrive at the receiving end. This is due to the lower wave velocity in sheath. Moreover, due to the 
higher attenuation constant of the sheath, the surge voltage gets significantly attenuated away from the cable entrance.

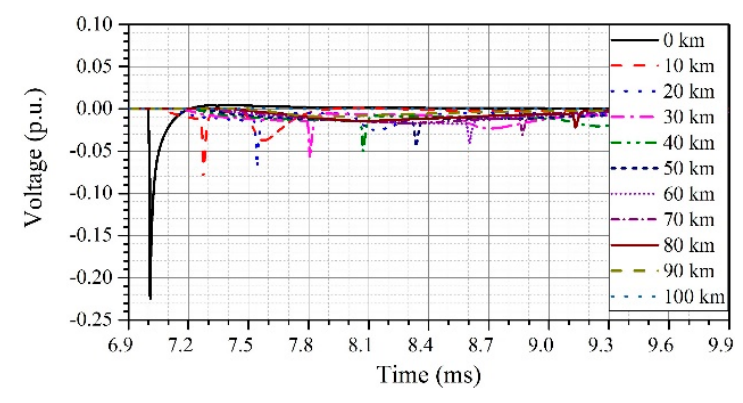

(a) $100 \mathrm{~km}$ cable

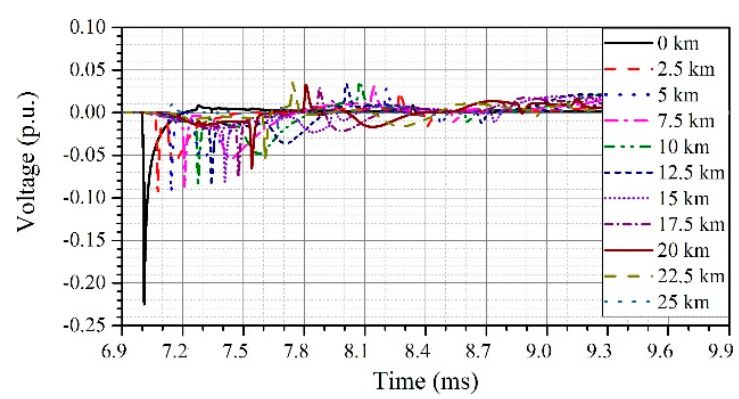

(c) $25 \mathrm{~km}$ cable

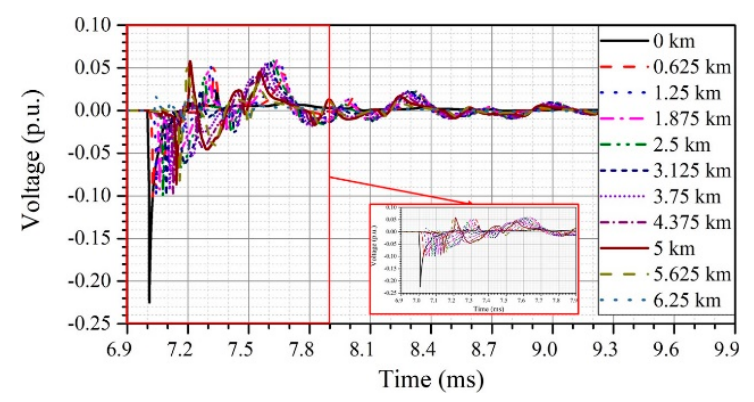

(e) $6.25 \mathrm{~km}$ cable

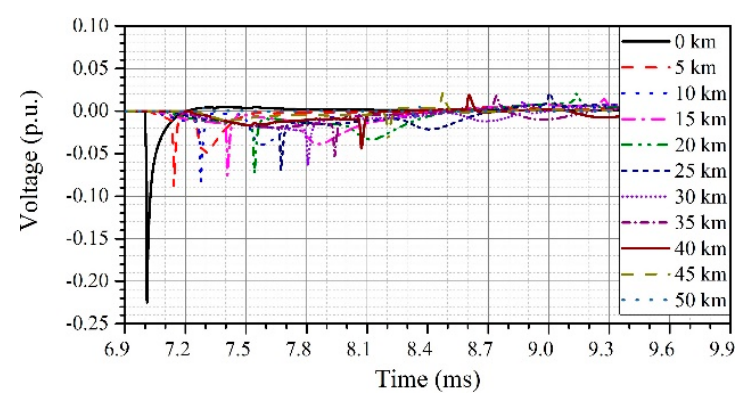

(b) $50 \mathrm{~km}$ cable

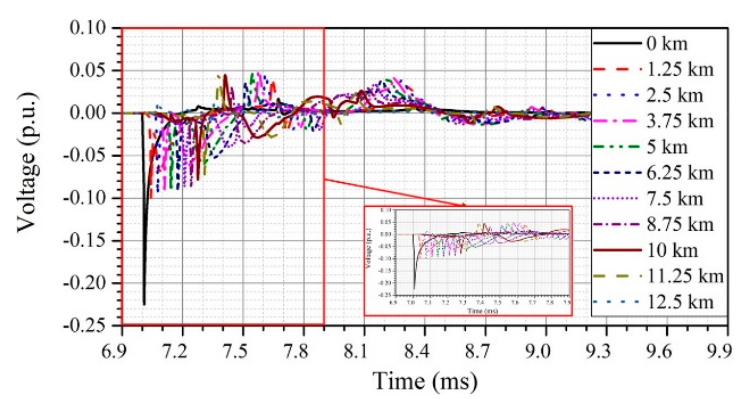

(d) $12.5 \mathrm{~km}$ cable

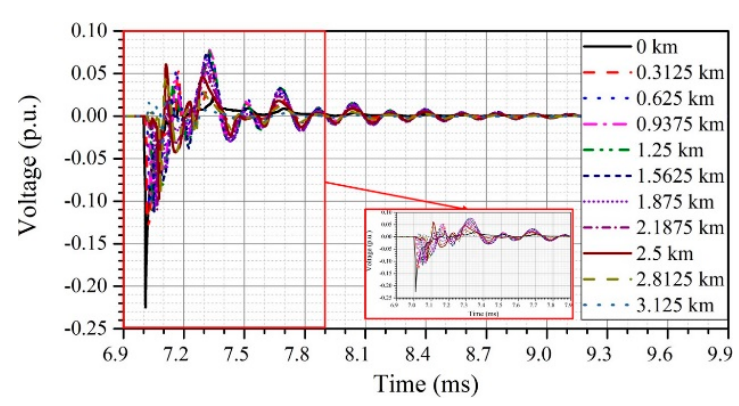

(f) $3.125 \mathrm{~km}$ cable

Figure 13. Sheath-ground overvoltage at ten equally spaced intervals along the length of a cable $(3.125-100 \mathrm{~km})$.

In the smaller cable sections ( $50 \mathrm{~km}, 25 \mathrm{~km}, 12.5 \mathrm{~km}, 6.25 \mathrm{~km}$ and $3.25 \mathrm{~km}$ ) the opposite polarity reflected surge arrives at the sending end within the time frame shown in Figure 13.

The sheath is grounded at both ends. Since the sheath grounding impedance is smaller than the characteristics impedance of the sheath, the reflection coefficient is negative, resulting in the positive polarity reflected waves. Therefore, the portion of the voltage surge reflected from the receiving end terminal cannot cause the amplification of the voltage even in very small cable sections. The maximum sheath voltage will always appear at the cable entrance regardless of its length.

The sheath-ground voltage along the length of the cable in cables with different total lengths is shown in Figure 14. Contrary to the core-ground voltages seen in Figure 11, the SG voltage is maximum at the cable entrance regardless of the cable length and reduces significantly at the receiving ends of the cable. 


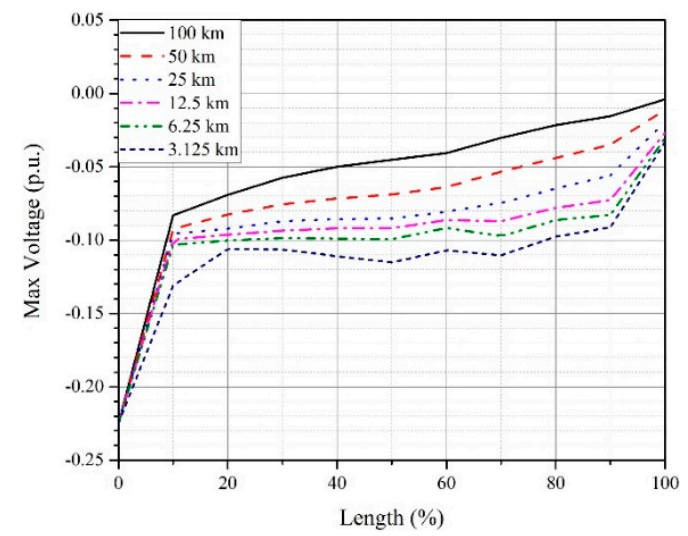

Figure 14. Maximum sheath-ground voltage along the length in cables with different lengths.

\subsubsection{Lightning Strikes on an Overhead Ground Wire/Tower Top}

A lightning strike on an OHGW/tower top results in voltage surge travelling along the OHGW in the reverse and forward directions, along with part of the wave travelling along the tower in the downward direction, as shown in the equivalent circuit of Figure 15.

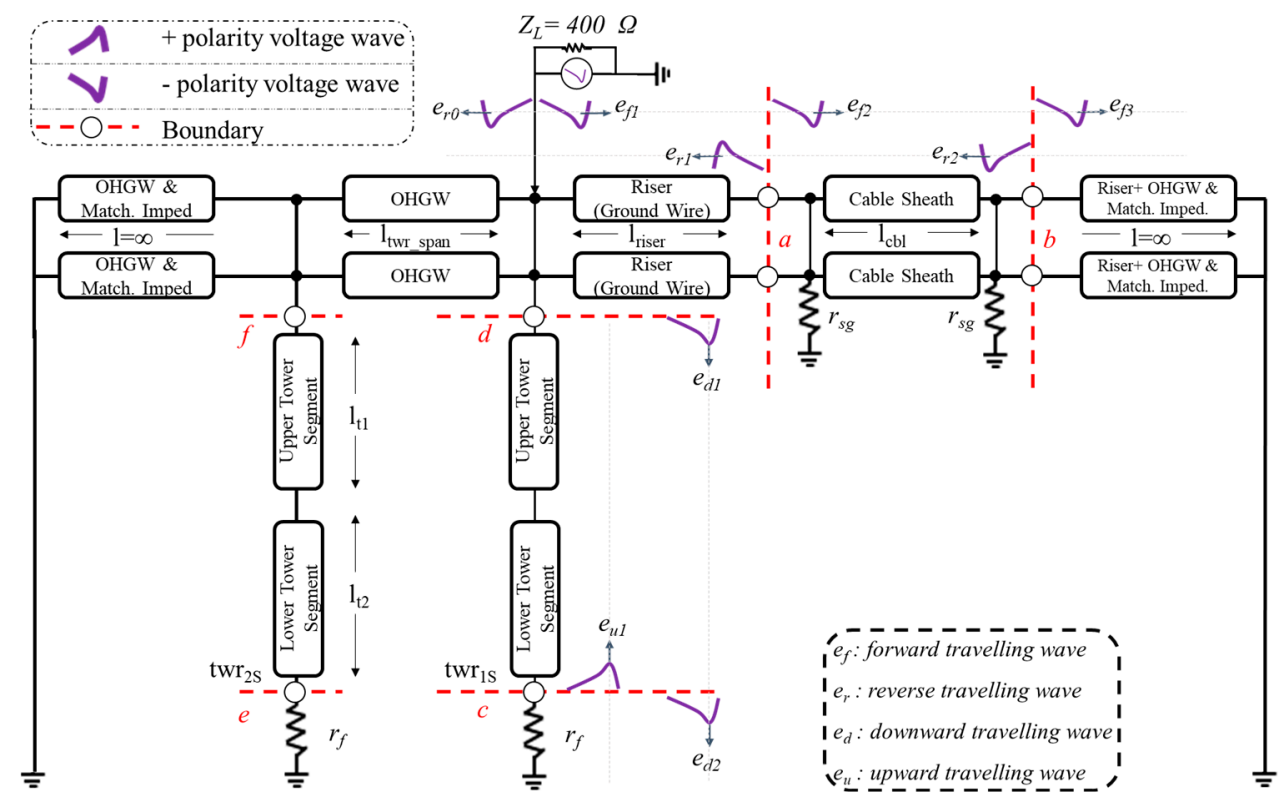

Figure 15. An equivalent circuit of a mixed HVDC transmission line for analysis of a lightning strike on the OHGW/tower top (only the two towers closest to the sending end of the cable are shown) (description of symbols is provided in Table 1).

When lightning strikes the OHGW/tower top far away from the cable, the major portion of the surge travels through the towers and is absorbed by the ground. Therefore, in this section we will only consider the OHGW strikes at the transition tower. A part of the voltage surge travels towards the cable through the riser section resulting in sheath-ground overvoltage. The simulation results of sheath-ground overvoltage at the entrance of the cable according to cable lengths are shown in Figure 16.

It can be seen that SG overvoltage at the sending end terminal is the same in all cases regardless of the cable length. Moreover, it can be noticed that the magnitude of the voltage in this case is about four times higher than that resulting from the OHPC strike. The SG voltage at equally spaced intervals along the length of cable are shown in Figure 17. 


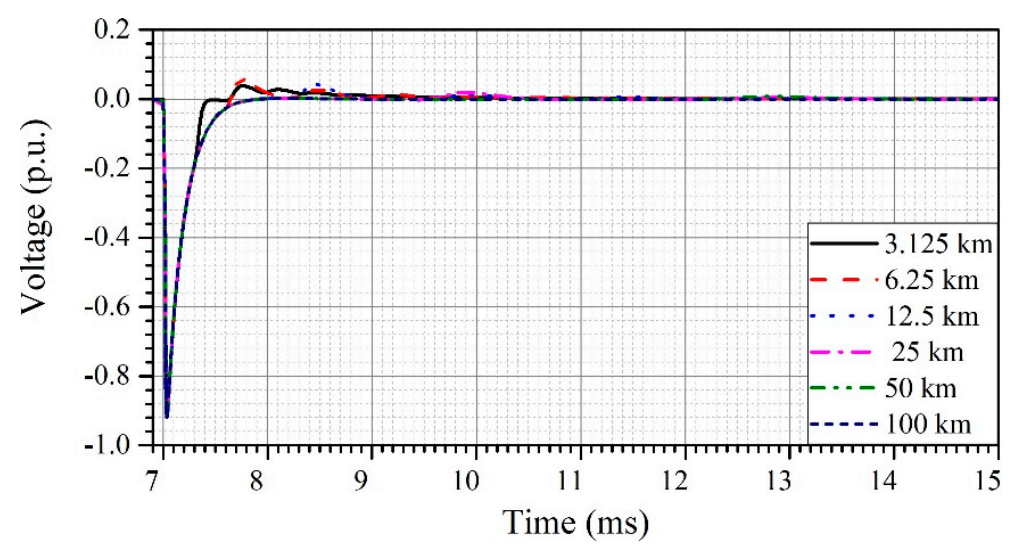

Figure 16. Sheath-ground overvoltage at the sending end terminal of the cables considering different cable lengths.

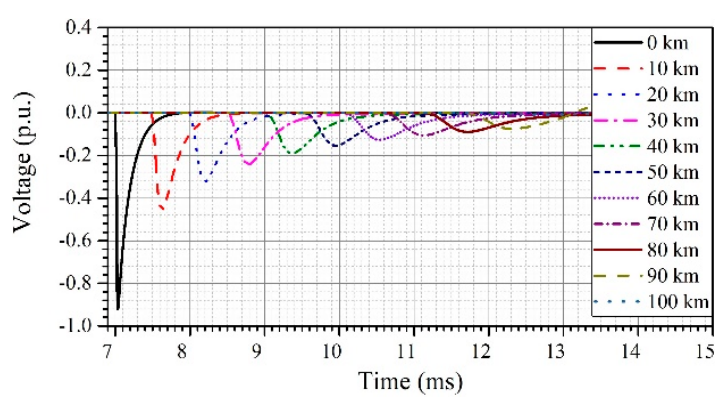

(a) $100 \mathrm{~km}$ cable

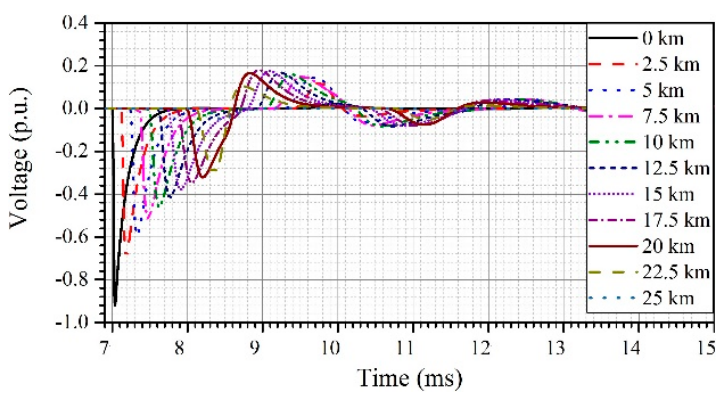

(c) $25 \mathrm{~km}$ cable

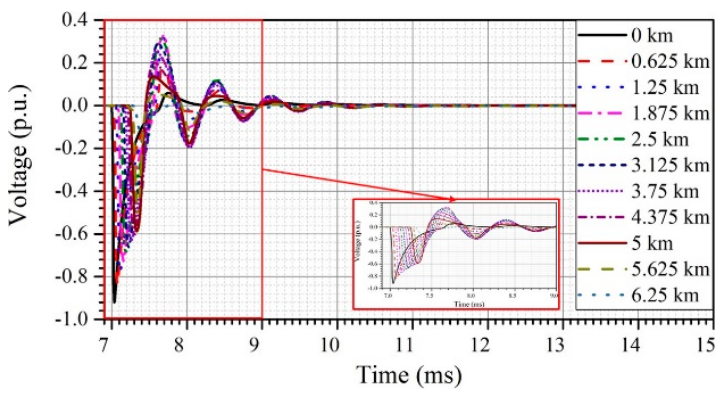

(e) $6.25 \mathrm{~km}$ cable

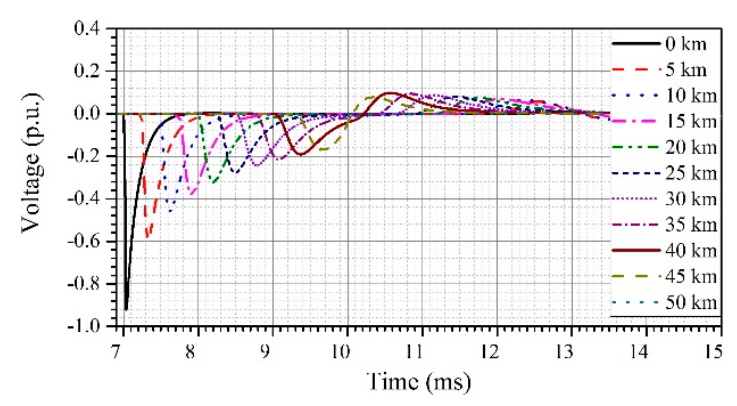

(b) $50 \mathrm{~km}$ cable

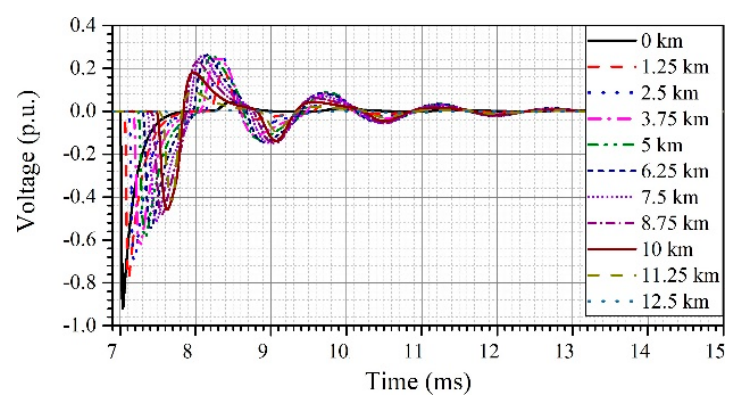

(d) $2.5 \mathrm{~km}$ cable

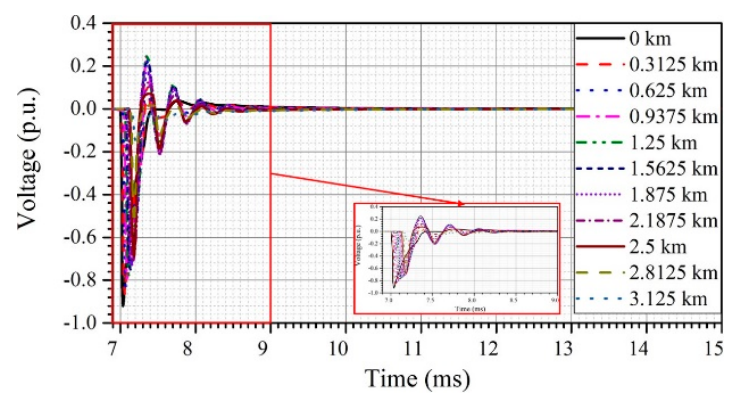

(f) $3.125 \mathrm{~km}$ cable

Figure 17. Sheath-ground overvoltage at ten equally spaced intervals along the length of the cable $(3.125-100 \mathrm{~km})$. 
It can be noted again that the SG voltage decreases exponentially along the length of cable due to a high attenuation constant. Moreover, even in the smallest cable sections, the reflected waves cannot cause amplification of the voltage inside the cable due to the negative reflection coefficient at boundary ' $b$ ' as shown in Figure 15. The comparison of voltage magnitude along the length of the cable in cables with different lengths is shown in Figure 18.

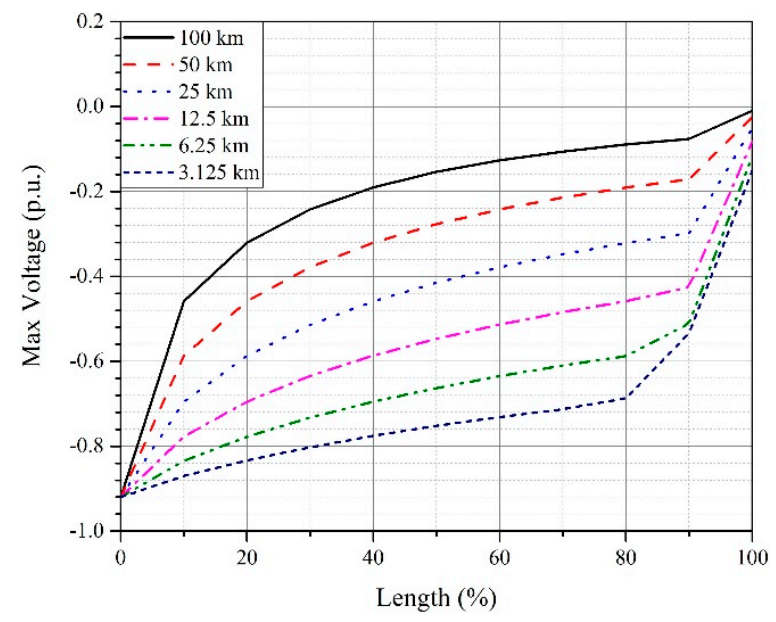

Figure 18. Maximum sheath-ground voltage along the length in cables with different lengths.

\subsection{Insuation Coordination Requirement}

The stress on the insulation layers of the cable must be limited to acceptable levels to prevent the insulation failure under the influence of lightning strikes. If the CG overvoltage exceeds the desired LIPL the surge arrester should be installed at the terminals of the cable between the core and the ground, whereas if the SG voltage exceeds the desired LIPL of the jacket, the sheath grounding impedance must be lowered. The schematic of the surge arrester installed at the cable terminals is shown in Figure 19.

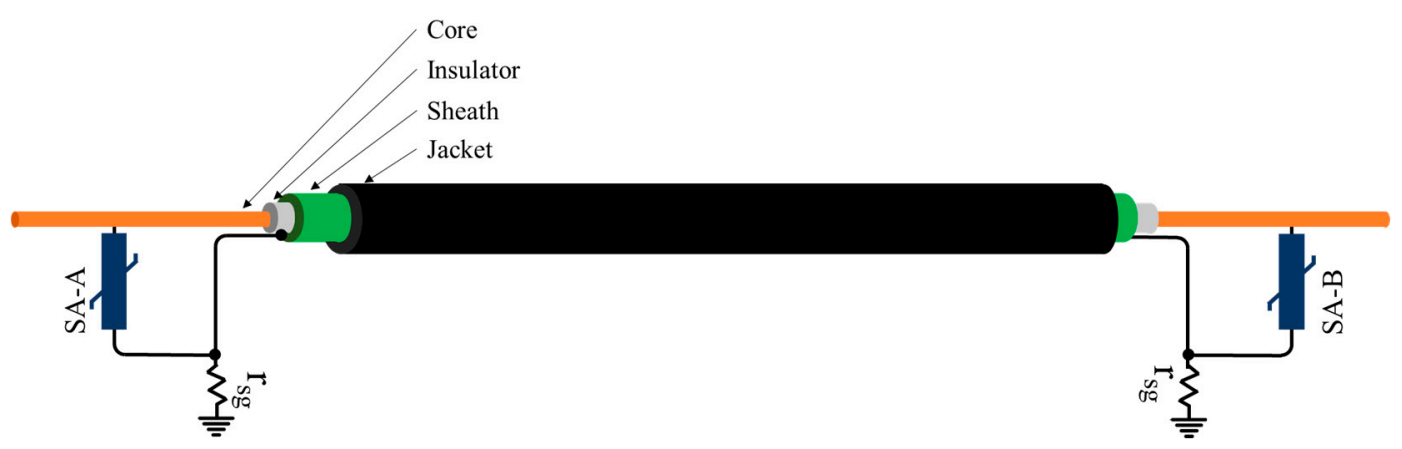

Figure 19. Location of surge arresters.

\subsubsection{Core-Ground Overvoltage}

The LIWL of the HVDC cable in this work is 2.7 p.u. Surge arresters as shown in Figure 19 will be applied at cable terminals if the CG voltage inside the cable exceeds the LIPL, i.e., 2.25 p.u., ensuring a protection margin of $20 \%$.

The direct lightning strike has been applied at the negative OHPC of the sending end transition tower. Cable lengths in the range of $2.5 \mathrm{~km}$ to $100 \mathrm{~km}$ (with an increment of $2.5 \mathrm{~km}$ ) are considered. The transient voltage in each case is measured at ten equally spaced intervals along the length of the cable. The maximum overvoltage in each case is recorded and plotted according to the length of the cable as shown in Figure 20. 


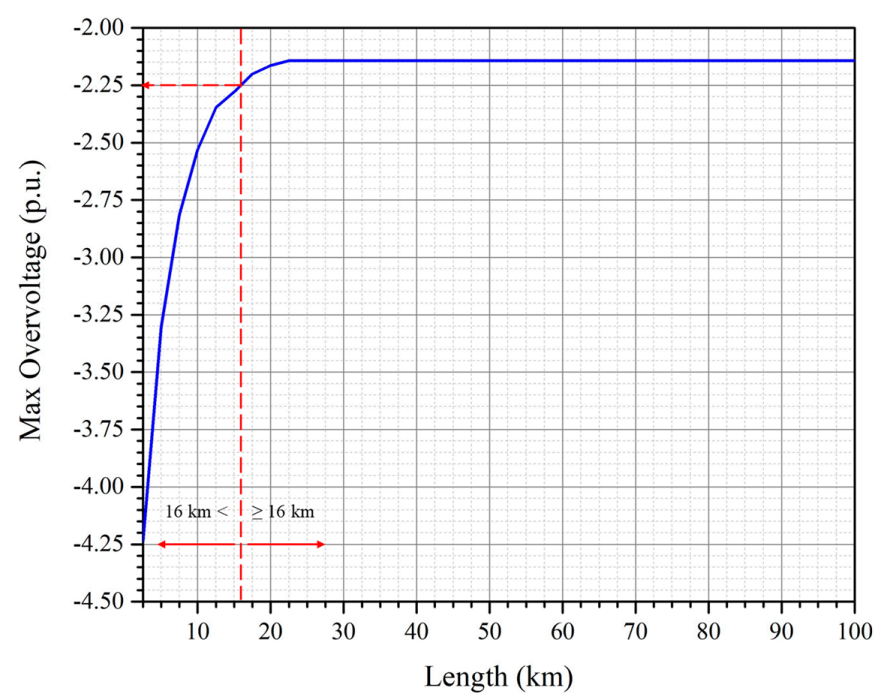

Figure 20. Maximum core-ground overvoltage according to the cable length.

It can be seen that the overvoltage exceeds 2.25 p.u. only if the cable length is shorter than $16 \mathrm{~km}$. For cable lengths greater than $22.5 \mathrm{~km}$, the cable overvoltage does not vary by changing the length of the cable. This implies that the reflection of the voltage surge from the receiving end of the cable takes sufficiently long to arrive at the sending end that amplification of the voltage is not possible. In such cases the maximum overvoltage always occurs at the sending end of the cable as can also be seen in Figure 11. Therefore, for this particular case of mixed HVDC transmission lines, the surge arrester should always be installed at the terminal of cables shorter than $16 \mathrm{~km}$.

\subsubsection{Sheath-Ground Overvoltage}

\section{Overhead Power Conductor Strike}

It can be seen that in the worst case OHPC strike, i.e., at the sending end transition tower, SG overvoltage is about 0.22 p.u., significantly higher than the desired LIPL of 0.1667 p.u. However, the magnitude of the overvoltage is independent of the length of the cable.

The SG overvoltage at the terminal of the sheath according to the sheath grounding impedance is shown in Figure 21. It can be seen that the maximum overvoltage can be limited to the desired protective level if the sheath grounding impedance is limited up to $6.5 \Omega$.

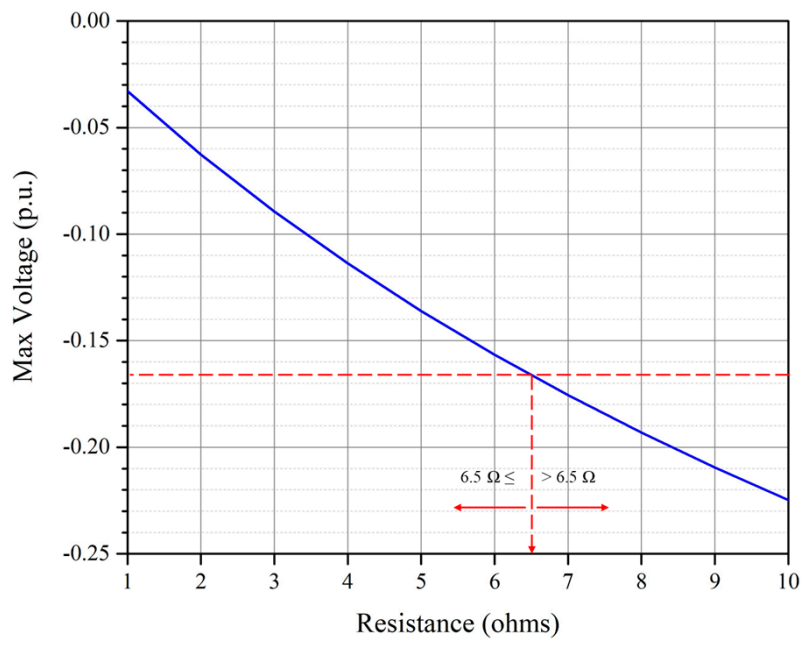

Figure 21. Maximum sheath-ground overvoltage at the entrance of the cable resulting from a lightning strike on the negative OHPC at the transition tower. 
Overhead Ground Wire/Tower Top Strike

In the worst case OHGW strike, i.e., at the sending end transition tower, overvoltage is more than five times the desired protective level. The maximum overvoltage in this case is also independent of the cable length and occurs at the sending end of the cable. The SG overvoltage at the terminal of the cable according to resistance of local ground is shown in Figure 22. It can be seen that the maximum overvoltage can be limited to the desired protective level if sheath grounding resistance is limited up to $1.2 \Omega$.

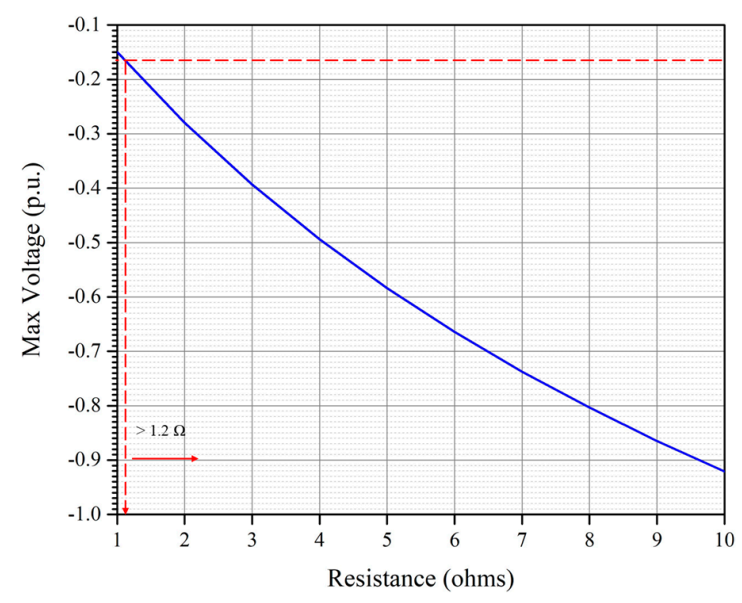

Figure 22. Maximum sheath-ground overvoltage at the entrance of the cable resulting from a lightning strike on OHGWs at the transition tower.

\subsection{Insulation Coordination: Impact and Analysis}

\subsubsection{Core-Ground Overvoltage}

The surge arresters are installed at both terminals of the cable as shown in Figure 19. The direct lightning strike is applied at the OHPC of the sending end transition tower. The maximum overvoltage along the length of cable is shown in Figure 23.

It can be seen that the overvoltage exceeds the desired protective level of the surge arrester only in the case of the smallest cable. However, it is still within the LIWL of the insulation. Therefore, damage to the cable is unlikely.

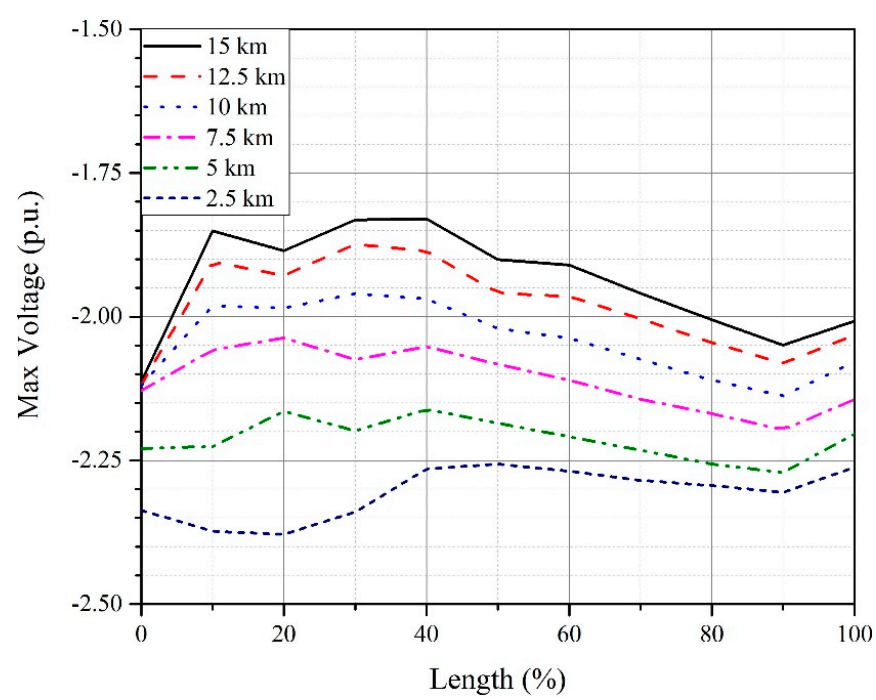

Figure 23. Core-ground overvoltage along the length of the cable with a surge arrester installed at the terminals. 


\subsubsection{Sheath-Ground Overvoltage}

The SG overvoltage along the length of the cable resulting from a direct lightning strike on the negative OHPC at the transition tower is shown in Figure 24. Despite the presence of surge arresters, the SG overvoltage exceeds the desired protective level of 0.16 p.u. in all cases.

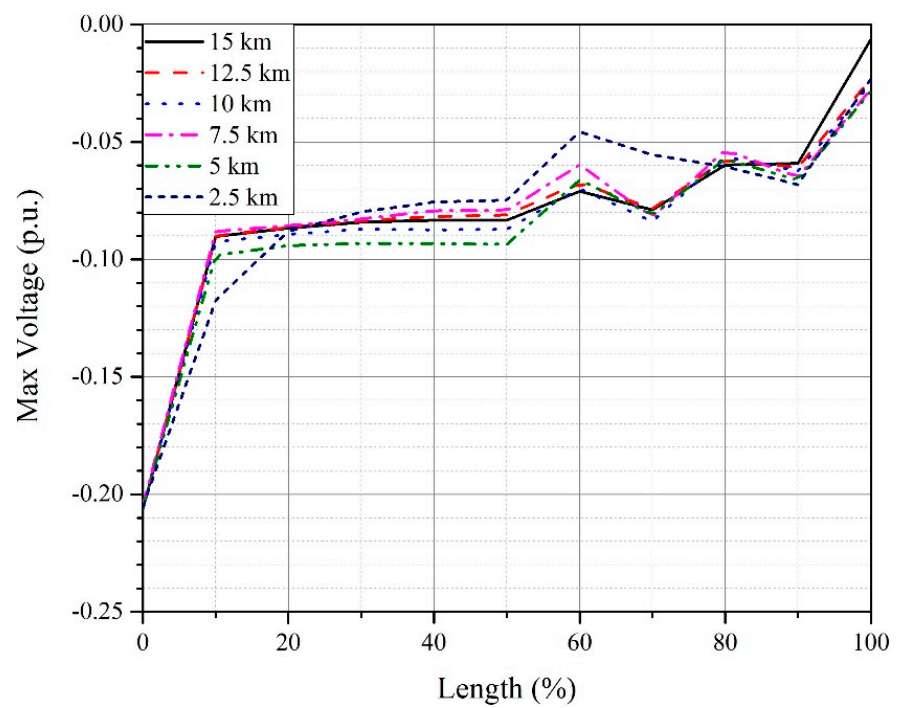

Figure 24. Sheath-ground (SG) overvoltage along the length of cable with a surge arrester installed at the terminals.

The energy dissipation in surge arresters installed at both ends of the line is shown in Figure 25. It can be seen that energy dissipation in the receiving end arrester is larger than the sending end regardless of the length of the cable. Moreover, energy dissipation becomes higher with the decrease in the length of the cable.

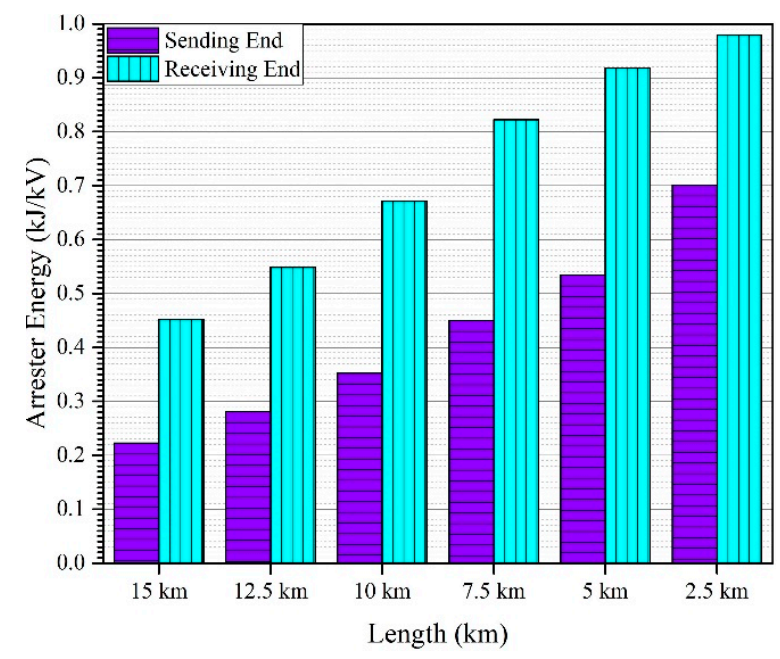

Figure 25. Surge arrester energy according to the length of the cable.

\subsubsection{Flashover Performance of Overhead Line Insulators}

In our previous research [15] we determined that the negative pole insulator of $\mathrm{twr}_{2 \mathrm{~S}}$ is most vulnerable to flashover in cases of direct lightning strike on the negative OHPC on $\operatorname{twr}_{2 \mathrm{~S}}$, whereas the positive pole insulator is most vulnerable in cases of indirect lightning strike on the OHGW or tower top. In this section, we have analyzed the impact of insulation coordination measures on the flashover performance of $\mathrm{twr}_{2 \mathrm{~S}}$ insulators. 
Strike on Overhead Power Conductors

A lightning strike is applied to a negative OHPC at the subsequent tower, i.e., $\mathrm{twr}_{2 S}$. The flashover performance with or without a surge arrester at the cable terminals is shown in Figure 26.

In our previous study [15] negative pole insulators of $\mathrm{twr}_{2 S}$ and $\mathrm{twr}_{3 S}$ were found to be most vulnerable. It can be seen in Figure 26 that the presence of a surge arrester at the cable terminal has virtually no impact on the insulator voltage. The insulator flashover occurs at both towers regardless of the presence of a surge arrester.

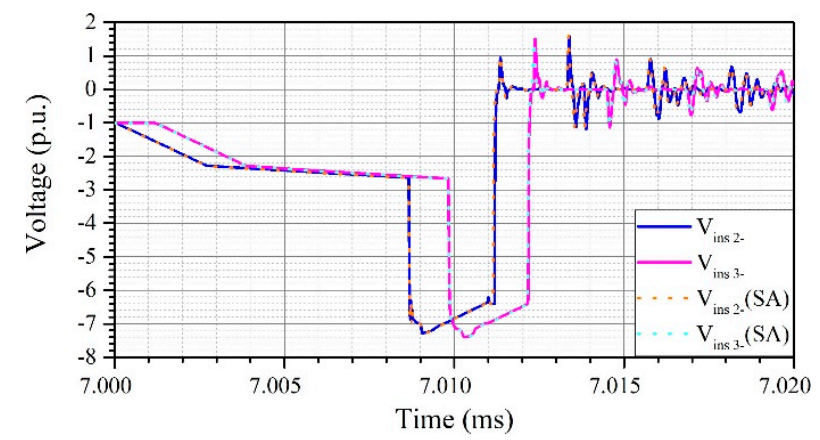

(a)

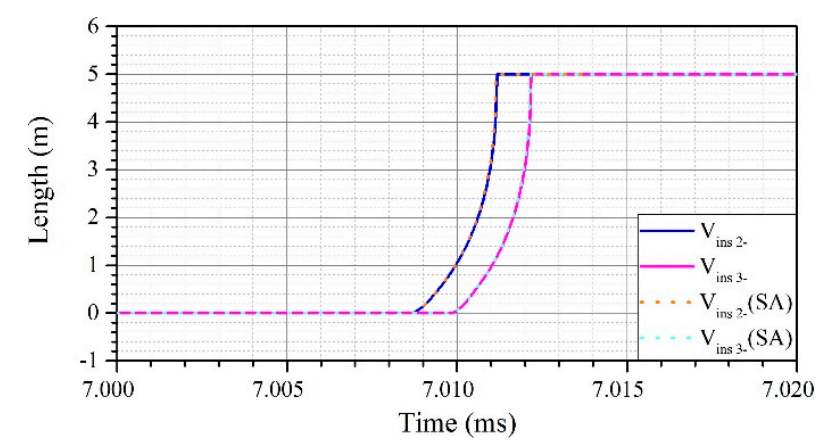

(b)

Figure 26. Lightning strike on the negative pole OHPC at $\mathrm{twr}_{2 \mathrm{~s}}$. (a) Voltage across negative pole insulators of $\mathrm{twr}_{2 S}$ and $\mathrm{twr}_{3 S}$. (b) Leader propagation between insulator arc horns of $\mathrm{twr}_{2 S}$ and $\mathrm{twr}_{3 S}$.

Strike on Overhead Ground Wire/Tower Top

In our previous study [15] we determined that in cases of lightning strike on the top of various towers, the plus pole insulators were most vulnerable to flashover. In the case of the lightning strike on the top of $\mathrm{twr}_{2 \mathrm{~S}}$, the plus pole insulator of $\mathrm{twr}_{2 S}$ always experienced a flashover. The sheath grounding impedance ' $r_{\mathrm{sg}}$ ' was assumed to be constant, i.e., $10 \mathrm{ohms}$ in that study. We have however, concluded that a low value of ' $r_{s g}$ ' is necessary in order to achieve the desired protective level for the sheath of HVDC cables.

The flashover performance of the $\mathrm{twr}_{2 S}$ insulator considering varying sheath grounding impedances is shown in Figure 27.

It can be seen that lowering the sheath grounding impedance has virtually no effect on the flashover performance of a plus pole insulator. Due to the much higher characteristic impedance of OHGW compared to the sheath grounding impedance, any change in its value has a marginal effect on the reflection coefficient at the boundary of the cable. The impact of footing impedance of $\mathrm{twr}_{2 S}$ on flashover performance of its plus pole insulator is presented in Figure 28. 


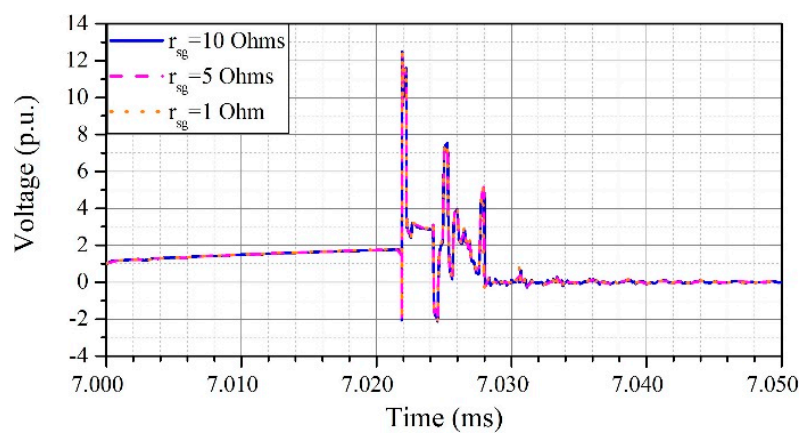

(a)

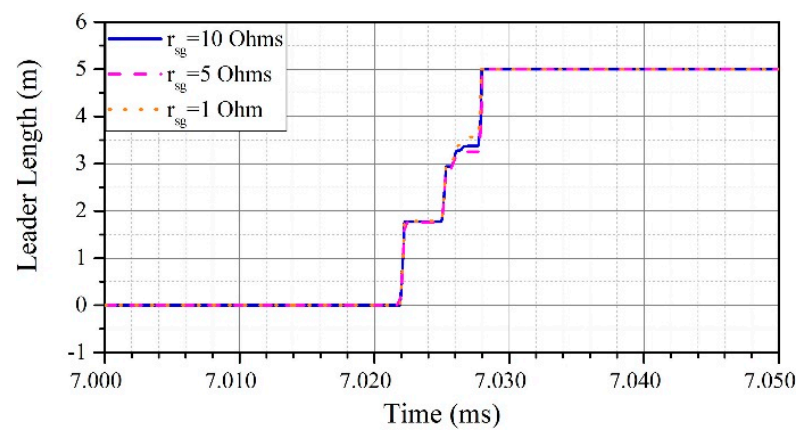

(b)

Figure 27. Lightning strike on the top of $\mathrm{twr}_{2 \mathrm{~S}}$. (a) Voltage across positive pole insulators of $\mathrm{twr}_{2 \mathrm{~S}}$ according to sheath grounding impedance. (b) Leader growth between insulator gap of $\mathrm{twr}_{2 S}$ according to sheath grounding impedance.

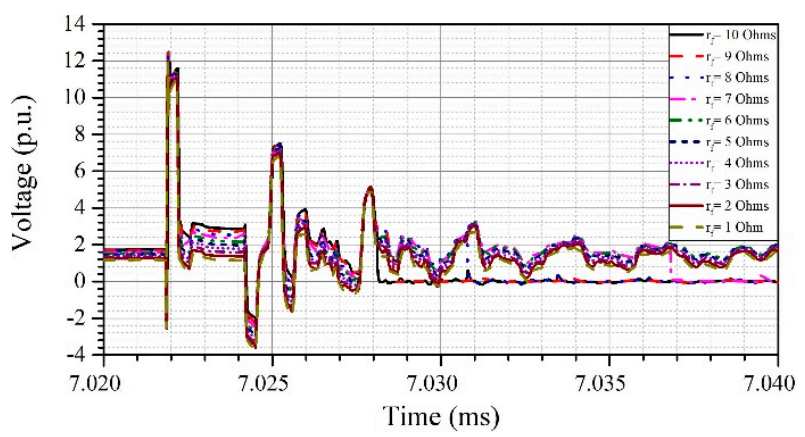

(a)

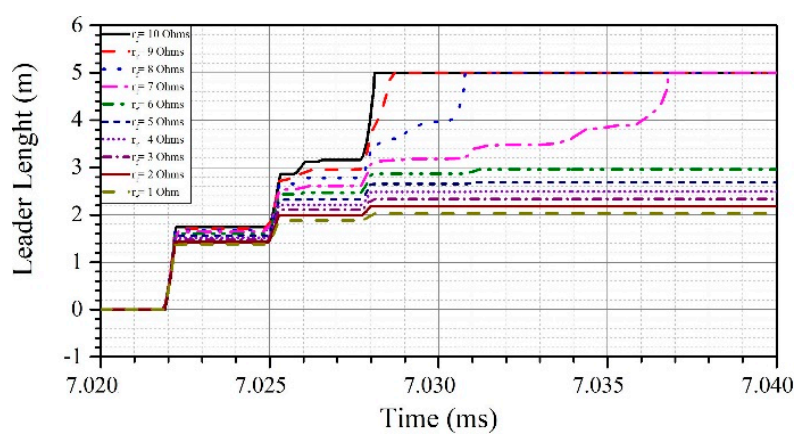

(b)

Figure 28. Lightning strike on the top of $\mathrm{twr}_{2 S}$. (a) Voltage across insulators of the positive pole of $\mathrm{twr}_{2 S}$ according to footing impedance. (b) Leader propagation between the insulator gap of $\operatorname{twr}_{2 S}$ according to footing impedance. 
It can be seen that by lowering the tower footing impedance to $6 \mathrm{ohms}$ the flashover of the insulator can be prevented. Lowering the footing impedance increases the reflection coefficient at the boundary c in Figure 8, resulting in an increased damping of voltage on the top of the tower.

\section{Conclusions}

Lightning strikes on the overhead section of the line subject the components of mixed HVDC transmission line to tremendous overvoltage stresses. These overvoltage stresses can cause flashover of OHL insulators and can cause cable insulation to fail permanently if they exceed the LIWL of the insulation layers.

The following outcomes have been drawn from this paper.

1. The maximum core-ground overvoltage increases with a decrease in the length of the cable. This behavior is experienced due to a positive reflection coefficient at the receiving end boundary of the cable. For cables, shorter than $16 \mathrm{~km}$, the magnitude of overvoltage is expected to exceed the LIPL of the cable. Therefore, surge arresters should be installed at the terminals of such cables.

2. The maximum sheath-ground overvoltage is independent of the length of the cable due to the negative reflection coefficient at the receiving end boundary of the sheath.

3. The sheath-ground overvoltage can exceed the LIWL of the jacket significantly for high sheath grounding impedances. The SG overvoltage can be limited within the LIPL of the jacket by limiting the sheath grounding impedance up to $1.2 \mathrm{ohms}$.

4. As concluded in our previous work [15] the sending end subsequent tower " $\mathrm{twr}_{2 \mathrm{~S}}$ " is most vulnerable to flashover in the case if OHPC as well as OHGW strikes. The flashover due to OHGW strikes can be prevented by limiting the footing impedance of $\operatorname{twr}_{2 S}$ to $6 \mathrm{ohms}$.

The presence of surge arresters on cable terminals does not impact the flashover performance of OHL insulators.

Author Contributions: Conceptualization, M.A. and B.-W.L.; methodology, M.A.; software, M.A. and A.S.; validation, M.A.; resources, K.-H.P. and H.-Y.L.; writing—original draft preparation, M.A.; writing-review and editing, B.-W.L.; project administration, H.-Y.L.; funding acquisition, B.-W.L.; supervision, B.-W.L.

Funding: This work was supported by the Korea Electric Power Corporation, Republic of Korea (Grant number. R17XA05-3). The APC was funded by Korea Electric Power Corporation.

Conflicts of Interest: The authors declare no conflict of interest. The funders had no role in the design of the study; in the collection, analyses, or interpretation of data; in the writing of the manuscript, or in the decision to publish the results.

\section{References}

1. Jovcic, D.; Ahmed, K. Introduction to line commutated HVDC. In High Voltage Direct-Current Transmission Converters, 2nd ed.; Wiley: West Sussex, UK, 2019; Volume 1, pp. 1-3.

2. Siepmann, W.; Kirby, N.M.; Xu, L.; Luckett, M. HVDC transmission for large offshore wind farms. Power Eng. J. 2002, 16, 135-141.

3. CIGRÉ Brochure 496. Recommendations for Testing DC Extruded Cable Systems for Power Transmission at a Rated Voltage up to 500kV; Working Group B1.32; CIGRÉ: Paris, France, 2012.

4. IEC 62067. Power Cables with Extruded Insulation and Their Accessories for Rated Voltages above $150 \mathrm{kV}(170 \mathrm{kV})$ up to $500 \mathrm{kV}(550 \mathrm{kV})$ - Test Methods and Requirements; Report; IEC: Geneva, Switzerland, 2011.

5. CIGRÉ Brochure 86. Overvoltages on HVDC Cables Final Report; Joint Working Group 33/21/14.16; CIGRÉ: Paris, France, 1994.

6. Bui-Van, Q.; Beaulieu, G.; Huynh, H.; Rosenqvist, R. Overvoltage studies for the St. Lawrence river 500-kV DC cable crossing. IEEE Trans. Power Deliv. 1991, 6, 1205-1215. [CrossRef]

7. Goertz, M.; Wenig, S.; Gorges, S.; Kahl, M.; Beckler, S.; Christian, J.; Suriyah, M.; Leibfried, T. Lightning overvoltages in a HVDC Transmission System comprising Mixed Overhead-Cable Lines. In Proceedings of the International Conference on Power System Transients, Seoul, Korea, 26-29 June 2017. 
8. Goertz, M.; Wenig, S.; Hirsching, C.; Kahl, M.; Suriyah, M.; Leibfried, T. Analysis of Extruded HVDC Cable Systems Exposed to Lightning Strokes. IEEE Trans. Power Deliv. 2018, 33, 3009-3018. [CrossRef]

9. Silva, F.F.; Pedersen, K.S.; Bak, C.L. Lightning in hybrid cable overhead lines and consequent transient overvoltages. In Proceedings of the International Conference on Power System Transients, Seoul, Korea, 26-29 June 2017.

10. Henriksen, T. Calculation of lightning overvoltages using EMTP. In Proceedings of the International Conference on Power System Transients, Lisbon, Portugal, 3-7 September 1995.

11. Colla, L.; Gatta, F.M.; Geri, A.; Lauria, S. Lightning overvoltages in hv-ehv "mixed" overhead-cable lines. In Proceedings of the International Conference on Power System Transients, Lyon, France, 4-7 June 2007.

12. Massaro, F.; Morana, G.; Musca, R. Transient behaviour of a "mixed" overhead-cable EHV line under lightning events. In Proceedings of the International Universities Power Engineering Conference, Glasgow, UK, 1-4 September 2009.

13. Hoogendorp, G.; Popov, M.; van der Sluis, L. Lightning Induced Overvoltages in Mixed 380 kV OHL-Cable-OHL connections. In Proceedings of the International Conference on Power System Transients, Vancouver, BC, Canada, 18-20 July 2013.

14. Gomes, T.V.; Schroeder, M.A.O.; Alipio, R.; de Lima, A.C.S.; Piantini, A. Investigation of Overvoltages in HV Underground Sections Caused by Direct Strokes Considering the Frequency-Dependent Characteristics of Grounding. IEEE Trans. Electromagn. Compat. 2018, 60, 2002-2010. [CrossRef]

15. Asif, M.; Lee, H.-Y.; Khan, U.A.; Park, K.-H.; Lee, B.W. Analysis of Transient Behavior of Mixed High Voltage DC Transmission Line Under Lightning Strikes. IEEE Access 2019, 7, 7194-7205. [CrossRef]

16. Lennerhag, O.; Lundquist, J.; Engelbrecht, C.; Karmokar, T.; Bollen, M.H.J. An Improved Statistical Method for Calculating Lightning Overvoltages in HVDC Overhead Line/Cable Systems. Energies 2019, 12, 3121. [CrossRef]

17. Ametani, A.; Kawamura, T. A Method of a Lightning Surge Analysis Recommended in Japan Using EMTP. IEEE Trans. Power Deliv. 2005, 20, 867-875. [CrossRef]

18. Ametani, A.; Nagaoka, N.; Ohno, T.; Baba, Y. Transient on Overhead Lines. In Power System Transients: Theory and Applications, 2nd ed.; CRC Press: Boca Raton, FL, USA, 2017; Volume 1, pp. 176-193.

19. Ishii, M.; Kawamura, T.; Kouno, T.; Ohsaki, E.; Shiokawa, K.; Murotani, K.; Higuchi, T. Multistory transmission tower model for lightning surge analysis. IEEE Trans. Power Deliv. 1991, 6, 1327-1335. [CrossRef]

20. Datsiso, Z.G.; Mikropoulous, P.N. Effect of tower modelling on the minimum backflashover current of overhead transmission lines. In Proceedings of the 19th International Symposium on High Voltage Engineering, Pilsem, Czech Republic, 23-28 August 2015.

21. Martinez, J.A.; Castro-Aranda, F. Tower modeling for lightning analysis of overhead transmission lines. In Proceedings of the IEEE Power Engineering Society General Meeting, 22-25 May 2005; IEEE: San Francisco, CA, USA, 2005; pp. 1345-1350.

22. A Simplified Method for Estimating Lightning Performance of Transmission Lines. IEEE Trans. Power Appar. Syst. 1985, PAS-104, 918-932. [CrossRef]

23. Chisholm, W.; Chow, Y.; Srivastava, K. Travel Time of Transmission Towers. IEEE Trans. Power Appar. Syst. 1985, PAS-104, 2922-2928. [CrossRef]

24. Alipio, R.; Visacro, S. Frequency Dependence of Soil Parameters: Effect on the Lightning Response of Grounding Electrodes. IEEE Trans. Electromagn. Compat. 2013, 55, 132-139. [CrossRef]

25. Cavka, D.; Mora, N.; Rachidi, F. A Comparison of Frequency-Dependent Soil Models: Application to the Analysis of Grounding Systems. IEEE Trans. Electromagn. Compat. 2014, 56, 177-187. [CrossRef]

26. Imece, A.F.; Durbak, D.W.; Elahi, H.; Kolluri, S.; Lux, A.; Mader, D.; McDemott, T.E.; Morched, A.; Mousa, A.M.; Natarajan, R.; et al. Modeling guidelines for fast front transients. IEEE Trans. Power Deliv. 1996, 11, 493-506.

27. CIGRÉ Technical Brochure 63. Guide to Procedures for Estimating the Lightning Performance of Transmission Lines; Working Group 33.01; CIGRÉ: Paris, France, 1991.

28. IEC Technical Report 60071-4. Insulation Co-Ordination -Part 4: Computational Guide to Insulation Co-Ordination and Modelling of Electrical Networks, 1st ed.; Report; IEC: Geneva, Switzerland, 2004.

29. Morched, A.; Gustavsen, B.; Tartibi, M. A universal model for accurate calculation of electromagnetic transients on overhead lines and underground cables. IEEE Trans. Power Deliv. 1999, 14, 1032-1038. [CrossRef] 
30. Gustavsen, B.; Irwin, G.; Mangelrød, R.; Brandt, D.; Kent, K. Transmission Line Models for the Simulation of Interaction Phenomena Between Parallel AC and DC Overhead Lines. In Proceedings of the International Conference on Power System Transients, Budapest, Hungary, 20-24 June 1999.

31. Stern, E.; Nash, C.; Shhoeniger, C.; Bartzsch, C.; Acquaotta, G.; Bacchini, M.; Orini, A. The Neptune regional transmission system $500 \mathrm{kV}$ HVDC project. In Proceedings of the Conseil International des Grands Réseaux Electriques, Paris, France, 24-29 August 2008.

32. Bewley, L.V. Travelling Waves on Transmission System, 1st ed.; Dover: New York, NY, USA, 1963; Volume 1.

33. Chowdhuri, P.; Anderson, J.G.; Chisholm, W.A.; Field, T.E.; Ishii, M.; Martinez, J.A.; Marz, M.B.; McDaniel, J.; McDermott, T.E.; Mousa, A.M.; et al. Parameters of lightning strokes: A review. IEEE Trans. Power Deliv. 2005, 20, 346-358. [CrossRef]

34. Mikropoulos, P.N.; Tsovilis, T.E. Lightning attachment models and maximum shielding failure current of overhead transmission lines: Implications in insulation coordination of substations. IET Gener. Transm. Distrib. 2010, 4, 1299-1313. [CrossRef]

35. Modeling of metal oxide surge arresters. IEEE Trans. Power Deliver. 1992, 7, 302-309. [CrossRef]

(C) 2019 by the authors. Licensee MDPI, Basel, Switzerland. This article is an open access article distributed under the terms and conditions of the Creative Commons Attribution (CC BY) license (http://creativecommons.org/licenses/by/4.0/). 